\title{
5 Die Minderheiten des NDH und die Besatzer
}

Wie bereits dargestellt war der Unabhängige Staat Kroatien ein multiethnischer Staat. In Anbetracht eines nicht unbedeutenden autonomen politischen Spielraums gegenüber Deutschland hatte die Ustascha, wie auch andere Verbündete Deutschlands, den Krieg als Gelegenheit genutzt, eine Lösung der Minderheitenfrage innerhalb seiner nationalen Grenzen vorzunehmen und für die Zeit nach dem Krieg bereits vollendete Tatsachen zu schaffen. ${ }^{1}$ Dies umfasste eine rassische Hierarchisierung der Bevölkerung, ihre Unterteilung in staatstragende und nicht staatstragende Gruppen sowie die Verfolgung von Juden, Serben und Roma.

Die heterogene Komposition des Staates nahmen auch Deutschland und Italien wahr. Ihre eigene Ideologie, die die Welt rassisch hierarchisierte, begünstigt durch die interethnischen Spannungen im Königreich Jugoslawien vor dem Krieg, ließ sie die Bevölkerung durch die ethnisch gefärbte Brille wahrnehmen und entsprechend selektierten. Die Verfolgungen durch die Ustascha, die anhand der „rassischen“ und „ethnischen“ Trennlinien verliefen, wirkten sich verstärkend auf diese Tendenz aus. Im Umgang mit den unterschiedlichen Ethnien im NDH spiegelte sich zudem der jeweilige imperiale Zugang zum kroatischen Staat. So folgt die Unterteilung der Bevölkerung des NDH nach Ethnien in diesem, wie auch in anderen Kapiteln der Sichtweise der deutschen und italienischen Besatzer. Viele Beispiele zeigen jedoch, dass die ethnischen Gruppen mitnichten so starr waren, wie die Besatzer annahmen und dass die Zugehörigkeit zu einer Ethnie oft zeitlichen, familiären oder regionalen Spezifika geschuldet war. Unter den Muslimen gab es beispielsweise sowohl diejenigen, die ihre Eigenstädigkeit in Abgrenzung zu Kroaten und Serben betonten als auch Anhänger des kroatischen bzw. serbischen Nationalismus, während die UstaschaIdeologie versuchte, „die Muslime“ in den kroatischen Nationalkörper zu integrieren. Die Ustascha war sogar gewillt, einen Teil der Serben als „prawoslave Kroaten“ in die eigene Nation zu integrieren. ${ }^{2}$

\footnotetext{
1 Vgl. Deák, István: The Worst of Friends: Germany’s Allies in East Central Europe - Struggles for Regional Dominance and Ethnic Cleansing, in: Cattaruzza, Marina/Dyroff, Stefan/Langewiesche, Dieter (Hg.): Territorial Revisionism and the Allies of Germany in the Second World War: Goals, Expectations, Practices, New York [u.a.] 2013, S. 17-29; Korb: Im Schatten des Weltkriegs.

2 Goldstein, Ivo: Ustaška ideologija o Hrvatima muslimanske vjere i odgovor u časopisu Han$d z \check{a r}$, in: Radovi - Zavod za hrvatsku povijest 38 (2006), S. 259-277; Kisić Kolanović, Nada: Muslimanska inteligencija i islam u Nezavisnoj Državi Hrvatskoj, in: Časopis za suvremenu povijest 36 (2004), 3, S. 901-938, hier S. 908. Kisić Kolanović untersucht hier die versuchte Modernisierung des Isams durch die kroatische Nation. Zur Haltung der Ustascha gegenüber
} 
Die Interaktion der Besatzer mit der Bevölkerung spielte sich unter diesen Rahmenbedingungen ab und konnte grundsätzlich auf viele Arten erfolgen. Einen wichtigen Berührungspunkt stellte sicherlich die Ernährung dar, die im vorigen Kapitel bereits dargestellt worden ist. Darüber hinaus interagierten die beiden Armeen bei der Aufstandsbekämpfung mit der Bevölkerung. Dieser Aspekt wird später untersucht. Hier liegt der Fokus allgemein auf Interaktionen mit bestimmten Gruppen, die in der überwiegenden Mehrheit ethnisch bzw. religiös definiert waren. Auch wenn diese Gruppen durchaus durchlässig sein konnten, handelte es sich oft um deutlich voneinander abgegrenzte Bevölkerungsteile.

In diesem Rahmen werden auch zwei Bevölkerungsgruppen betrachtet, deren Stellung jeweils sehr speziell, wenn auch einander diametral entgegengesetzt war: Einerseits hatte die deutsche Volksgruppe eine besondere Stellung im NDH inne. Sie ist nur in ihrer Interaktion mit den reichsdeutschen Stellen interessant, da es eine Interaktion mit den italienischen Streitkräften oder Diplomaten nicht gegeben hat. Andererseits wird hier auch die jüdische Bevölkerung Kroatiens betrachtet, die als Gruppe besonderer Verfolgung mit dem Ziel ihrer Vernichtung ausgesetzt war. Waren die anderen Gruppen in unterschiedlichen Graden in der Lage, ihre Stellung im Staat zu verhandeln, fehlte der jüdischen Bevölkerung diese Option. Jüdische Personen traten dennoch als Agierende auf, indem sie versuchten, den Verfolgungen zu entkommen und sich dem Kampf gegen die Ustascha und die Achse anschlossen. Hier wird aber vor allem untersucht, welche Rolle Deutschland und Italien beim Holocaust im NDH spielten.

Die Verfolgung der Juden und der Roma stand im Einklang mit der deutschen Politik. Die Homogenisierung des Landes, die zudem durch die Verfolgung der Serben erreicht werden sollte, war ebenfalls mit dem nationalsozialistischen Gedankengut vereinbar. Hitler riet sogar wiederholt der kroatischen Staatsspitze dazu, eine „national intolerante“ Politik zu betreiben, um den Staat zu konsolidieren. ${ }^{3}$ Darüber hinaus spielte die Bevölkerung für die deutschen Akteure vor Ort zunächst keine Rolle. Der Verbündete und Ansprechpartner war

den Serben siehe: Bartulin: Ideologija nacije, S. 24 f.; Biondich, Mark: „We Were Defending the State“: Nationalism, Myth, and Memory in Twentieth-Century Croatia, in: Lampe, John/Mazower, Mark (Hg.): Ideologies and National Identities. The Case of Twentieth-Century Southeastern Europe, Budapest/New York 2004, S. 54-81, hier S. 63-66. Siehe auch die Mikrostudie von Max Bergholz, der zeigt, wie die in der Ortschaft Kulen Vakuf verübte Gewalt eine neue Wahrnehmung des eigenen ichs, der Gemeinschaft und auch der Etnizität auslöste. Bergholz, Max: Violence as a Generative Force: Identity, Nationalism, and Memory in a Balkan Community, Ithaca/London 2016.

3 So z. B. bei der Unterredung mit Pavelić am 6. Juni 1941, in: Hillgruber: Staatsmänner, Bd. 1, S. 575-580, hier S. 577. Siehe auch Schmider: Partisanenkrieg, S. 46. 
die Ustascha und über sie sollten deutsche Interessen durchgesetzt und gewahrt werden. Die Serben wurden vom ersten Kriegstag an als die Feinde betrachtet. ${ }^{4}$ Daher hielten sich sowohl alle deutschen diplomatischen Stellen als auch die Wehrmacht zunächst zurück und mischten sich nicht in die „inneren Angelegenheiten“ des kroatischen Staates ein. Doch trotz aller Zurückhaltung, angesichts der Gefahren, die die Ustascha-Verfolgungspolitik auch für die Ausbeutung des NDH mit sich brachte, wirkten die Deutschen zuweilen regulierend auf die Ustascha ein. Die Wehrmachtsführung versuchte im Frühjahr 1942 das italienische Vorgehen vom September 1941 nachzuahmen. Anstatt jedoch selbst tätig zu werden, sollte die Ustascha dazu gebracht werden, alle Bürger gleich zu behandeln und der Bevölkerung ein Gefühl der Sicherheit zu vermitteln. Natürlich schlossen solche Überlegungen Juden und Roma kategorisch aus. Doch übten die deutschen in dieser Hinsicht nicht genügend Druck aus, so dass alle Versuche in dieser Hinsicht scheiterten. ${ }^{5}$

Im Gegensatz zu Deutschland bemühte sich das faschistische Italien vom ersten Tag an, die Gunst der Bevölkerung in seinem Gebiet und, wenn möglich, darüber hinaus zu gewinnen. Die Ustascha stellte zwar den ersten Partner dar, doch kam es hier sehr schnell zu ersten Überwerfungen. Die kroatische Verfolgungspolitik wurde in Italien grundsätzlich viel kritischer gesehen. Im Gegensatz zu Hitler riet Mussolini Pavelić, vom Kampf gegen die Orthodoxen abzulassen, ,....nicht nur aus Humanitätsgründen, sondern auch weil es ein Fehler“ sei. ${ }^{6}$ Diese Haltung kann jedoch nicht ohne die italienischen Aspirationen in Kroatien verstanden werden. Die Annexion Dalmatiens führte unweigerlich zur Interaktion mit der dort ansässigen Bevölkerung. ${ }^{7}$ Doch auch der Kampf mit den kroatischen Behörden um die Vorherrschaft in den nicht annektierten Gebieten sowie die Verfolgungen der Serben, Juden und Roma führten zur Einmischung der italienische Armee, die in vielfachen Kontakten zur einheimischen Bevölkerung mündeten. Die Vorstellung, im italienischen spazio vitale zu agieren und der Wille, die faschistische Vorstellung vom Imperium mit allen Implikationen, die im zweiten Kapitel aufgezeigt worden sind, durchzusetzen, führte im Herbst 1941 schließlich zur Übernahme der Befehlsgewalt in der II. und teilweise in der III. Zone. Von da an war die Interaktion mit der Bevölkerung enger, wenn sie sich auch, je nachdem, um welche Bevölkerungsgruppe es sich han-

\footnotetext{
4 Siehe auch Kap. 8.2.

5 Korb: Im Schatten des Weltkriegs, S. $362 \mathrm{f}$.

6 Appunto per l'Eccellenza il sottosegretario di stato, 15.2.1943, abgedr. i. Talpo: Dalmazia, Bd. 3, S. $241 \mathrm{f}$. Der Duce äußerte sich auch gegenüber General Löhr in dieser Hinsicht kritisch. BArch, RH 31/III/9, Bl. 230, Besprechungen General - Generaloberst Löhr, 15.12.1942.

7 Die Italiener Dalmatiens hegten ihrerseits gewisse Sympathien gegenüber den Serben. Siehe Monzali: Gli italiani di Dalmazia, S. 379.
} 
delte, stark unterschied und stets den italienischen Zielen in diesem Gebiet untergeordnet war. Dies zeigt sich am deutlichsten bei der unterschiedlichen Behandlung der jüdischen, serbischen und muslimischen Bevölkerung, deren Vertreter sich alle, wenn auch in unterschiedlichem Maß, schutzsuchend an die italienische Armee wandten.

\subsection{Interaktionen mit der serbischen Bevölkerung}

Die Ustascha stilisierte die serbische Bevölkerung zu ihrem größten Feind. Bereits in den ersten Monaten nach der Gründung des NDH wurden Tausende Serben ermordet. ${ }^{8}$ Auf die Verfolgungen reagierten sie in manchen Gebieten mit spontanen Aufständen. Diese waren zunächst nur ein Versuch, das eigene Leben $\mathrm{zu}$ retten und ihre Dörfer $\mathrm{zu}$ beschützen. Obwohl beide Besatzer von der Heftigkeit der Verfolgungen überrascht waren, hatten beide Armeen die Anweisung, sich in diese ,innere Angelegenheit“ des NDH nicht einzumischen. Als Glaise von Horstenau in einem Telegramm bemerkte, aus der Wehrmacht käme die Anregung, gegen die Ustascha vorzugehen, hielt der Befehlshaber Südost ein solches Vorgehen für „unerwünscht“. 9 Einerseits waren in Kroatien sehr wenige deutsche Truppen stationiert, die tatsächlich in die Kämpfe hätten eingreifen können und andererseits waren und wurden serbenfeindliche Bilder in der Wehrmacht stark verbreitet. ${ }^{10}$ Die Wehrmacht hielt sich zunächst an diese Befehle. Das sollte sich mit dem fortschreitenden Krieg jedoch zumindest teilweise ändern.

In der italienischen Armee war die Lage eine andere. Aufgrund italienischer Gebietsgewinne im Nordosten des Landes nach dem Ersten Weltkrieg hatte Italien in Vergangenheit vor allem mit den dort ansässigen Kroaten und Slowenen Konflikte. Auch wenn Kroatien nun der offizielle Verbündete war, war in der Armee die Meinung weit verbreitet, dass die Kroaten (und nicht die Serben), Italien stets feindlich gesinnt waren, und es auch bleiben würden. ${ }^{11}$ Als die Verfolgungen der Serben einsetzten, berichteten italienische militärische Stellen darüber und intervenierten bei kroatischen Lokalbehörden, um die Verfolgungen zu stoppen. ${ }^{12}$ Das Ausmaß und die Art der Verfolgungen zogen Mitgefühl für die

8 Siehe Korb: Im Schatten des Weltkriegs, S. 127-136, 268-289.

9 BArch, RH 31/III/1, Bl. 29, Fernschreiben des Dt. Generals in Agram an das OKW, 10.7.1941. 10 Manoschek: Partisanenkrieg und Genozid, S. $139 \mathrm{f}$.

11 Bericht des Carabinieri-Generals Giuseppe Pièche, 18.1.1943, abgedr. i. Zbornik, XIII/3, Nr. 13, S. 47. Pièche sammelte in den besetzten und annektierten Gebieten Informationen über die Partisanen.

12 AUSSME, N 1-11, DS, b. 523, DS des 34. Rgt. Artiglieria „Sassari“, Eintrag vom 8.7.1941. 
Serben sowie Verachtung für den eigentlichen Verbündeten, die Kroaten, nach sich. So erklärte der Befehlshaber der Division „Sassari“ in Knin: „Wir können bei diesem Abschlachten, das die Ustascha angefangen haben, nicht zusehen. Die Ustascha sind an allem schuld. Aufständische Serben haben Recht. Sie kämpfen um ihr nacktes Leben. “13

Es dauerte schließlich nicht lange, bis italienische Offiziere und Soldaten eingriffen und den verfolgten Serben halfen. Dabei zeichneten sich insbesondere die in Knin stationierte Division Sassari sowie das gesamte VI. Armeekorps aus, in dessen Besatzungsgebiet sich viele Orte mit serbischer Bevölkerung befanden. Viele der Serben retteten sich durch Flucht in das von Italien annektierte Dalmatien, auch wenn Bastianini sie daran hindern wollte und zudem versuchte, serbische Flüchtlinge nach Serbien abzuschieben. Die Deutschen Besatzungsbehörden in Serbien vereitelten jedoch diesen Plan. ${ }^{14}$ Häufig reichte schon die Anwesenheit einer italienischen Abteilung oder Garnison, um die schlimmsten Exzesse zu verhindern. ${ }^{15}$ Für die Zeit bis zur Übernahme der militärischen Gewalt in der II. Zone sind zahlreiche Berichte erhalten, die von den Bemühungen der italienischen Soldaten zeugen, der unter den Ustascha-Angriffen leidenden serbischen Bevölkerung zu helfen. ${ }^{16}$ Sowohl in der Korrespondenz mit den Vorgesetzten als auch in der Kommunikation mit den kroatischen Beamten wird ein bestimmtes Argumentationsmuster deutlich. Das Eingreifen wurde als die „moralische Pflicht eines Kulturvolkes“ verteidigt, es erfolgte nach den „Gesetzen der Gerechtigkeit und der Humanität““ ${ }^{17}$ So erklärte beispielsweise der Befehlshaber der Division Sassari, General Furio Monticelli, sein Verhalten damit, dass er die Verfolgungen nicht mehr hören und sehen konnte. Deshalb habe er eines Nachts eine Gruppe Serben in drei Lastwägen über die Grenze nach Dalmatien gebracht - um ihre Leben zu retten. Dies hielt er für die Pflicht eines kultivierten Menschen. ${ }^{18}$

Doch ein solches Vorgehen stellte keine politisch gewollte Aktion Italiens dar. Einerseits handelte es sich um spontane Hilfestellungen einzelner Perso-

13 Bericht von David Sinčić, Leiter des Regionalbezirks von Birbir und Sidraga, 12.8.1941, abgedr. i. NOB u Dalmaciji, Bd. 1, S. 832-839, hier S. 836.

14 Ruzicic-Kessler: Italiener auf dem Balkan, S. $164 \mathrm{f}$.

15 Auszug aus dem Bericht des Verwaltungsbezirks Birbir und Sidraga, 17.6.1941, abgedr. i. NOB u Dalmaciji, Bd. 1, S. 788 f.; Telegramm der Königlichen Gesandtschaft ans Außenministerium, 24.5.1941, abgedr. i. Talpo: Dalmazia, Bd. 1, S. 388; Milizia ustascia, 11.6.1941, abgedr. i. Talpo: Dalmazia, Bd. 1, S. 468-471.

16 Vgl. Zbornik, V/1; Zbornik, XIII/1.

17 ASMAE, GAB-AP 1923-1943, b. 1493, Attività anticroata di serbi a Chistagne, 7.8.1941.

18 VA, NDH, k. 84, inv. br. 5/3, Informeller Bericht 16.-21.6.1941 für General Laxa vom 23.6.1941. 
nen, andererseits war es schlicht und einfach unmöglich, die Grenze zu Dalmatien dicht zu machen. Für die Behörden in Dalmatien sowie die Armee stellten die vielen Flüchtlinge ein Problem dar, auch weil der Eindruck vermieden werden sollte, dass „Dalmatien ein bequemer Zufluchtsort für die Feinde Kroatiens“ sei. ${ }^{19}$ Italienische Diplomaten warfen im Sommer 1941 der Armee „Philoserbismus“ vor. Die politische Führung in Rom wollte noch nicht auf offenen Konfrontationskurs mit der Regierung in Zagreb gehen, und so wurde den Soldaten angeordnet, sich nicht in die „lokalen Angelegenheiten“ einzumischen. ${ }^{20}$ Dieser Befehl galt jedoch nicht lange, denn bereits Anfang September besetzte die italienische Armee weite Teile des dalmatinischen Hinterlandes.

Mit der Bekanntmachung vom 7. September 1941 änderte sich der Umgang mit der serbischen Bevölkerung. Zunächst rief General Ambrosio alle auf, die in die Wälder geflüchtet waren, in ihre Dörfer zurückzukehren, während die italienische Armee ihnen Unversehrtheit, Freiheit und ihren Besitz garantierte. Italienische Militärbehörden sorgten sogar dafür, dass den Rückkehrern ihr Eigentum zurückgegeben wurde. Dafür setzten sie die bestehenden kroatischen Gesetze außer Kraft. Gemäß diesen fiel das Eigentum der Personen, die das Staatsterritorium verließen, dem Staat zu, wenn diese sich nach der Aufforderung nicht innerhalb von 15 Tagen bei der zuständigen Behörde meldeten. Den verlassenen Unternehmen wurden von der gleichen Behörde Vertrauenspersonen zugewiesen, die die Geschäftsführung für den Staat übernahmen. ${ }^{21}$ Solche Gesetze wurden nur dazu erlassen, einen legalen Rahmen zur Aneignung des Eigentums der vertriebenen oder geflüchteten Serben und Juden zu schaffen. Schon im ersten Gespräch mit dem kroatischen Verwaltungskommissar legte General Ambrosio diesem nahe, zurückkehrenden Serben ihr Eigentum zurückzugeben. Weiterhin sollten serbische Staatsangestellte ihre früheren Stellen zurück erhalten, wenn sie nur aufgrund ihrer Ethnie entlassen worden waren. Schließlich verlangte er, in den Gemeinden mit serbischer Mehrheit serbische

19 ASMAE, GAB-AP 1923-1943, b. 1493, Telegramm von Giuseppe Bastianini an das Außenministerium, GAB-AP, 5.8.1941; AUSSME, N 1-11, DS, b. 580, rac. 52, Nr. 6, Immigrazione in Dalmazia di serbo-ortodossi ed ebrei, 24.5.1941; AUSSME, N 1-11, DS, b. 580, rac. 53, Nr. 2, Affluenza di ebrei, serbo-ortodossi ecc. nei territori dalmati assegnati al Regno d'Italia, 25.5.1941. Der Gouverneur von Dalmatien bemühte sich nach Kräften, die 1.500 dorthin geflüchteten Serben wieder los zu werden. Da es in Italien nicht genügend Lager gab, und die Flüchtlinge als zu gefährlich eingestuft wurden, um sie unbewacht unterzubringen, ordnete das Innenministerium den Präfekturen an, alle Mittel einzusetzen, um die Flüchtlinge zur Rückkehr zu bewegen. ASMAE, GAB-AP 1923-1943, b. 1505, Rifugiati serbi in Dalmazia, 22.8.1941; ASMAE, b. 1505, Brief von Mameli an Bastianini, Dezember 1941.

20 Befehl vom 14.8.1941, abgedr. i. Zbornik, XIII/1, Nr. 116, S. 309.

21 Narodne Novine, Nr. 96 vom 07.8.1941, Verordnung Nr. 472; Narodne Novine, Nr. 7 vom 21.4.1941, Verordnung Nr. 24; Narodne Novine, Nr. 30 vom 17.5.1941, Verordnung Nr. 145. 
Gemeindevorsteher aufzustellen. ${ }^{22}$ Obwohl sich die kroatische Verwaltung wenig kooperativ zeigte, wurden diese Maßnahmen von den italienischen Militärbehörden umgesetzt. Sie führten wieder zu zahlreichen Protesten kroatischer Zivilbehörden, die sich auf bestehende kroatische Gesetze beriefen - Gesetze, die nach Ambrosio in der demilitarisierten Zone nicht galten. ${ }^{23}$ Die rechtlose Stellung der Serben wurde somit zumindest in der II. Zone aufgehoben. Italienische Militärbehörden sorgten dafür, dass den Zurückkehrenden ihr Besitz restituiert wurde, auch wenn dies bedeutete, dass die in der Zwischenzeit in ihren Häusern angesiedelten Kroaten diese wieder verlassen mussten. Auch die Vertrauenspersonen wurden aus den Unternehmen entfernt und diese an Verwandte der Geflüchteten übergeben. Von den kroatischen Behörden geschlossene serbische und jüdische Geschäfte durften wieder öffnen. ${ }^{24}$ Auch in der III. Zone, in der die italienischen Armee nur militärische Befugnisse hatte, beschützten italienische Kommandeure das Leben und Eigentum der Serben, wie zahlreiche Beschwerden der lokalen kroatischen Behörden dokumentieren. Beispielsweise schützte der Stadtkommandant in Ključ die Serben vor Übergriffen durch die Ustascha-Behörden. ${ }^{25}$

Wichtig für die serbische Bevölkerung war die Tatsache, dass nach dem 7. September 1941 alle Konzentrationslager und Gefängnisse in der II. Zone unter italienische Kontrolle kamen. Die Garnisonskommandos sollten alle Gefangenen samt der ihnen von den kroatischen Behörden vorgeworfenen Taten auflisten sowie ärztliche Kontrollen und Befragungen durchführen, um herauszufinden, wie sie behandelt und unter welchen Umständen sie verhaftet wurden. Das gesamte in den Gefängnissen vorhandene Material sollte nicht an die Kroaten herausgegeben werden. ${ }^{26}$ Doch die kroatischen Konzentrationslager auf der Insel Pag, in Vrbovno und Jablansko wurden bereits vorher geräumt. Die Insassen waren entweder ermordet oder in Lager auf deutschem Einflussgebiet transportiert worden. Um den Verbleib ihrer Angehörigen aufzuklären wandten sich

22 HDA, OUP, k. 46, Nr. 11709, Bericht des OUP, 6.9.1941.

23 VA, NDH, k. 61, reg. br. 38/18, Bericht für den Befehlshaber der kroatischen Truppen, Slavko Kvaternik, 23.8.1941; HDA, OUP, k. 8, Nr. 12719, Bericht aus Dubrovnik, Sept. 1941; Elementi di risposta alla nota n. 1395/41 dal 25 settembre 1941-XIX, presentata dalla Legazione di Croazia a Roma al Ministero degli esteri italiano, 9.10.1941, abgedr. i. Talpo: Dalmazia, Bd. 1, S. 629631.HDA, OUP, k. 3, Nr. 12073, Schreiben der 2. Armee an den OUP, 25.10.1941.

24 HDA, OUP, k. 3, Nr. 12063, Schreiben der Staatlichen Direktion für Erneuerung, 17.10.1941; NARA, T-821, R. 401, Nr. 22, Schreiben der 2. Armee, Abteilung für Zivilangelegenheiten, 17.4.1942; HDA, OUP, k. 1, Nr. 11786, Vertrauenspersonen in serbischen und jüdischen Geschäften werden entfernt, 9.9.1941; VA, NDH, k. 61, reg. br. 38/18, Bericht für den Befehlshaber der kroatischen Truppen, Slavko Kvaternik, 23.8.1941.

25 VA, NDH, k. 69, reg. br. 17/3, Bl. 7, Bericht des II. Domobranenkorps, Brod, 1.-16.2.1942. 26 VA, TV, k. 77, reg. br. 3/22, Situazione in Croazia e provvedimenti conseguenti, 18.8.1941. 
die Serben immer wieder an italienische Militärbehörden. Diese halfen zwar bereitwillig, ihre Nachfragen schmetterten die kroatischen Behörden jedoch meist mit der Auskunft ab, dass keine Informationen über den Verbleib der genannten Person existierten. ${ }^{27}$ Der kroatische Verwaltungskommissar versuchte vergeblich, diesen Nachfragen ein Ende zu bereiten. Er erklärte den italienischen Befehlshabern, dass ein Teil der verschwundenen Serben in kroatischen Lagern, ein anderer nach Bosnien und Serbien geflohen sei und von dort gegen die Achse kämpfe, und ein dritter Teil gegen die Untaten der Tschetniks-Kommunisten als Geisel gefangen genommen wurde. ${ }^{28}$ Doch Vertreter der italienischen Armee intervenierten auch, damit Serben aus der Haft entlassen wurden. Das Kommando der 2. Armee verlangte beispielsweise die Freilassung von 623 Serben in Mostar mit der Begründung, dass sich die Situation nicht normalisieren könne, wenn die Familien der arbeitsfähigen Männer beraubt blieben. ${ }^{29}$

Die Italienische Armee untersuchte zudem die im Sommer verübten Ustascha-Verbrechen: Massengräber auf Pag aber auch anderswo wurden ausgegraben und Opfer gezählt und nach Möglichkeit identifiziert und begraben. Kroatische Behörden aus Trebinje berichteten, dass die Italiener die Opfer zusammen mit ihren Familienangehörigen fotografierten und feierlich begruben. ${ }^{30}$ In Gacko, Bileća und Glamoč, wo ebenfalls Leichen exhumiert und anschließend begraben wurden, beschwerten sich kroatische Lokalbehörden über solch „eigenmächtiges Vorgehen“ der Italiener, doch konnten sie nichts dagegen ausrichten. ${ }^{31}$ Sogar einer der stärksten deutschen Kritiker der italienischen Politik im NDH, Glaise von Horstenau, beobachtete eine positive Wirkung italienischer Maßnahmen:

27 HDA, OUP, k. 5, Nr. 12209, Schreiben des Leiters des Regionalbezirks von Bribir und Sidraga an den Poglavnik, 3.11.1941; HDA, OUP, k. 5, Nr. 12270, Schreiben des Kommandos der 2. Armee an den OUP, 10.11.1941; HDA, OUP, k. 10, Nr. 13020, Bericht des OUP, 23.1.1942.

28 HDA, OUP, k. 10, Nr. 13020, Schreiben des OUP an die II. Armee, 23.1.1942.

29 HDA, OUP, k. 5, Nr. 12270, Kommando der 2. Armee an den OUP; Im März 1942 beschwerte sich General Roatta, dass in Dubrovnik noch 19 Personen im Gefängnis seien, obwohl sie nach der Amnestie von Opatija vom 25. Dezember 1941 freigelassen werden müssten. Zuvor hatten die Italiener schon verboten, dass diese Personen vor ein Ustascha-Sondergericht gestellt wurden, mit der Begründung, dass dies schlechte Auswirkungen auf die Bevölkerung haben würde. HDA, OUP, k. 14, Nr. 13489, II. Armee an den OUP, 25.3.1942.

30 HDA, OUP, k. 4, Nr. 12172, Schreiben von Adem Avdić: Situation in Bosnien, 27.10.1941.

31 HDA, OUP, k. 9, Nr. 12825, Schreiben des Verwaltungsbezirks Dubrava an das Innenministerium und den OUP, 6.10.1941; HDA, OUP, k. 9, Nr. 12835, Exhumierung der Orthodoxen im Bezirk Bileća, 18.10.1941; HDA, OUP, k. 9, Nr. 12837, Schreiben des Befehlshabers der 2. Armee an den OUP, 2.12.1941. 
Die Regimefeindlichkeit der ital. Militärbehörden äußert sich allerdings auch in einer auch den ansässigen Kroaten sympathischen Maßnahme: durch betonte Untersuchung der Ustascha-Gräueltaten (Ausgrabung der Leichen Ermordeter usw.) und Lahmlegung der Ustascha, wodurch im ital. Besatzungsgebiet nicht selten ein größeres Gefühl der Rechtssicherheit entsteht, als es im deutschen Vorhanden ist. ${ }^{32}$

In ihrem Bemühen, die Lebensbedingungen der Serben wieder zu normalisieren, missachteten italienische Behörden weitere kroatische Gesetze. Sie setzten sich für die Eröffnung von Schulen in serbischen Dörfern ein sowie auch für die Benutzung der kyrillischen Schrift, die im NDH verboten war. ${ }^{33}$ Orthodoxe Kirchen wurden wieder eröffnet und Liturgien abgehalten, obwohl es den orthodoxen Priestern verboten war, kirchliche Funktionen auszuüben. ${ }^{34}$ Daher verwundert es nicht, dass man in den Unterlagen des Verwaltungskommissars viele Beschwerden kroatischer Beamter über das Vorgehen der Italiener findet. Insbesondere verfolgten und dokumentierten sie das unterschiedliche Verhalten der italienischen Soldaten gegenüber Kroaten (und Muslimen) einerseits und Serben andererseits. ${ }^{35}$

In mehreren Ortschaften verhinderten italienische Befehlshaber im März 1942 die Einberufung der orthodoxen Reservisten, die nicht in der Armee dienen durften, aber gemäß einem deutsch-kroatischen Abkommen nach Deutschland zum Arbeitsdienst in die Betriebe der Reichsluftwaffe geschickt werden sollten. ${ }^{36}$ Italienische Ortskommandanten erklärten den kroatischen Behörden, dass Einberufungen zwar ausgehändigt, jedoch die Rekruten nicht gezwungen werden durften, diesen Folge zu leisten. Bei öffentlichen Versammlungen rieten sie zudem den Serben, den Einberufungen zur Arbeit nicht Folge zu leisten. Das Ergebnis dieser Haltung war schließlich, dass sich beispielsweise in Hrvatske Moravice auch nach mehrmaligem Eingreifen der kroatischen Behörden, die verkündeten, dass die Einberufenen dem kroatischen Militärgesetz unterstanden und notfalls auch polizeilich vorgeführt werden würden, keiner der 162 Serben meldete. In Vrbovsko erschienen von den sechzehn einberufenen immerhin

32 BArch, RH 31/III/1, Bl. 109, Fernschreiben des Dt. Bev. Generals in Kroatien vom Oktober/ November 1941.

33 ASMAE, GAB-AP 1923-1943, b. 1505, Funzionamento delle scuole nella zona demilitarizzata, 21.10.1941.

34 HDA, OUP, k. 1, Nr. 11823, Schreiben an das Außenministerium, 15.9.1941; HDA, OUP, k. 4, Nr. 12146, Bezirksamt Nevesinje an die Staatliche Direktion für Erneuerung, 18.9.1941; HDA, OUP, k. 4, Nr. 12163, Eröffnung von orthodoxen Kirchen, 25.9.1941.

35 VA, NDH, k. 61, reg. br. 38/18, Bericht für den Befehlshaber der kroatischen Truppen, Slavko Kvaternik, 23.8.1941.

36 VA, NDH, k. 248, reg. br. 12/4-2; VA, NDH, k. 320, reg. br. 5/2-2, Schreiben des Verteidigungsministeriums an das Außenministerium, 1.5.1942. 
zwei. ${ }^{37}$ Dieses Vorgehen der Italiener schlug hohe Wellen, und schließlich wurde der kroatische Verteidigungsminister, Slavko Kvaternik, verständigt, um eine Intervention bei den italienischen Behörden $\mathrm{zu}$ veranlassen, damit sich einzelne italienische Offiziere nicht in die Interessen der kroatischen Regierung einmischten. Kvaternik meldete die Vorfälle auch dem Deutschen General in Kroatien. ${ }^{38}$

Auch nach dem „Zagreber Vertrag“ vom Juni 1942, der den teilweisen Rückzug der Italiener regelte, sowie der Übernahme der Aufgaben für die Aufrechterhaltung der öffentlichen Ordnung durch den NDH, blieben Serben und Juden geschützt. Mit einem geheimen Zirkular wies der damalige kroatische Polizeichef alle an, Vorfälle mit den italienischen Behörden „energisch zu vermeiden“. Lokalbehörden sollten gute Beziehungen zu den Italienern aufbauen und Strafmaßnahmen gegen Serben und Juden vermeiden. ${ }^{39}$ Dies passte auch zu der neuen kroatischen Politik, die auf Druck der Besatzer nach einem modus vivendi mit den Serben suchte. Im Zuge dieser Politik wurden auch ca. 300 serbische Frauen und Kinder aus dem Lager Loborgrad entlassen. ${ }^{40}$ Trotzdem kam es immer wieder vor, dass insbesondere die orthodoxe Bevölkerung aus Angst vor neuen Verfolgungen mit den Italienern mitgehen wollte. ${ }^{41}$

Die spontane Hilfe der italienischen Einheiten für die serbische Bevölkerung stellte auch einen ersten Grundstein für die Annäherung der italienischen Armee an die Tschetniks dar. Gleichzeitig nahmen die italienischen Soldaten das Verhalten der serbischen Bevölkerung ihnen gegenüber als freundlich und hilfsbereit wahr, während das Verhalten der Kroaten als feindlich und das der Muslime als abwartend beschrieben wurde. ${ }^{42}$ Ein besonders markantes Beispiel ereignete sich bei der Division „Re“. Bewaffnete Serben, also höchstwahr-

37 BArch, RH 31/III/8, Gemeindeamt Hrvatske Moravice an das Landwehrergänzungsbezirkskommando Karlovac, 25.3.1942, sowie dieses an das kroatische Landwirtschaftsministerium, II. Abt. vom 30.3.1942.

38 BArch, RH 31/III/8, Schreiben des Dt. Bev. Generals in Kroatien an die Gesandtschaft in Zagreb, 1.4.1942.

39 Kovačić: Odnos policijsko-obavještajne službe Nezavisne Države Hrvatske prema Italiji, S. 943.

40 Rosenberg, Dragutin: Bericht über die Lage der Juden in Jugoslawien 1941-1943, in: Levental, Zdenko: Auf glühendem Boden. Ein jüdisches Überlebensschicksal in Jugoslawien 19411947, hgg. v. Erhard Roy Wiehn/Jacques Picard, Konstanz 1994, S. 215-257, hier S. 238 f.; Korb: Im Schatten des Weltkriegs, S. 362.

41 ASMAE, GAB-AP 1923-1943, b. 1497, Trasferimento di popolazione croate al seguito delle nostre truppe, 5.4.1943; AUSSME, N 1-11, DS, b. 772, All. 230, al DS Giugno 1942, Sgombero di Petrovac, 9.6.1942.

42 ASMAE, GAB-AP 1923-1943, b. 1497, Situazione a Mostar, 17.10.1941; ASMAE, GAB-AP 19231943, b. 1497, Situazione in Erzegovina, 23.10.1941. 
scheinlich eine Tschetnik-Gruppe, halfen einer italienischen Abordnung, die sich mit den Garnisonseinkäufen auf dem Rückweg zu ihrer Garnison befand, vier zerstörte Brücken zu überqueren und ließen sie zu ihrer Sicherheit von zwei Männern begleiten. Als es zu spät wurde, um weiter zu fahren, bot ihnen die serbische Bevölkerung Unterkünfte an, die diese annahmen. Dabei wurde den italienischen Soldaten berichtet, dass die Serben nur darauf warteten, dass die Italiener wieder ihre Gegend besetzten, um ihre Arbeit wieder aufzunehmen und die Waffen abzugeben. ${ }^{43}$

Darüber hinaus existierte unter den italienischen Offizieren eine gewisse Sympathie für Serben, die aus der liberalen Zeit herrührte, als beide eine gegen Österreich-Ungarn gerichtete Politik betrieben. Das italienische Königshaus war zudem mit den herrschenden serbischen und montenegrinischen Königshäusern verwandt. Im Gegensatz dazu verfolgten die Italiener eifersüchtig die guten deutsch-kroatischen Beziehungen, die auf die gemeinsame Zeit in der habsburgischen Armee zurückgeführt wurden. ${ }^{44}$ Dies weist darauf hin, dass die Erinnerung an die Konstellationen aus dem Ersten Weltkrieg weiterhin eine Rolle spielte. Während Italiener und Serben gegen Österreich-Ungarn gekämpft hatten, hatten Kroaten in habsburgischen Einheiten gedient.

Hinzu kam, dass die großserbische und pro-Alliierte Orientierung, welche die Tschetniks in Serbien von Anfang an auszeichnete, in der ersten Phase der Aufstände in Kroatien noch fehlte. Die Tschetniks, die sich im italienischen Besatzungsgebiet im Sommer 1941 formiert hatten, waren lokale Wehren, die die serbische Bevölkerung vor weiteren Übergriffen der Ustascha beschützen sollten. ${ }^{45}$ Sie verstanden es darüber hinaus, das italienische Verlangen nach Prestige zu stillen, was ihnen zusätzliche Vorteile brachte. Bereits Anfang Mai 1941 forderte ein serbischer Anführer „im Namen von 100.000 Serben aus Norddalmatien“ die Italiener dazu auf, ganz Dalmatien zu annektieren. Nach der Unterzeichnung der Römischen Verträge sollte die Annexion auf mit Serben besiedelte Teile von Bosnien und Lika ausgeweitet werden. ${ }^{46}$ Besonders geschickt

43 AUSSME, N 1-11, DS, b. 449, All. 2, Relazione I ${ }^{\circ}$ Reg. Fant. Re an Comando Divisione Fant. Re, 31.7.1941. Auch die kroatischen Behörden meldeten die herzlichen Beziehungen zwischen Serben und italienischen Offizieren und Soldaten. So hatten Italiener in Ogulin zwei Messen in orthodoxen Kirchen abgehalten, an welchen auch Serben teilnahmen. Bericht der Verwaltungsbezirk Modruš vom 31.3.1942, abgedr. i. Zbornik, V/3, Nr. 164, S. 554-558.

44 Monzali: La difficile alleanza, S. 95; BArch, RH 31/III/12, Privatbrief Glaise von Horstenaus an Generaloberst Löhr, 13.1.1943.

45 Nikolić: Italijanska vojska i četnici, S. 33.

46 Sobolevski, Mihael: Uloga Četnika u Nezavisnoj Državi Hrvatskoj, in: Časopis za suvremenu povijest 27 (1995) 3, S. 475-488, hier S. 480. 
gingen die Tschetniks auch beim Angriff auf Knin im Juli 1941 vor, indem sie sich gleichzeitig an das italienische Kommando wandten:

Die Bevölkerung von Lika bittet die italienische Armee darum, sofort die ganze Zone der Provinz zu besetzen, weil sie wegen kroatischer Unterdrückung nicht mehr leben kann. Wir erwarten sie sehnlichst. Die Bevölkerung und die Tschetniks. ${ }^{47}$

Weitere Bitten wurden an Mussolini oder an die italienischen Kommandeure gerichtet, in Kroatien die Macht zu ergreifen und die Serben zu retten. ${ }^{48}$ Im August 1941 kam es zu mehreren Treffen zwischen italienischen Offizieren und Tschetnik-Führern. ${ }^{49}$ Serbische Aufständische erklärten, nicht gegen die italienische Armee zu operieren, wenn diese nicht mit der Ustascha zusammen arbeitete, sondern im Gegenteil Sympathien und Hochachtung für die italienische Armee zu hegen. Am 1. August 1941 eroberten Tschetniks Ervenik, wonach die Italiener in der Stadt einmarschierten und die Tricolore hissten. In der anschließenden, nach italienischen Angaben „herzlichen“ Rede hob der Tschetnik-Führer Italien, den Duce und die italienischen Truppen, die Frieden und Freiheit bringen würden, anerkennend hervor. ${ }^{50}$ Nach der Wiederbesetzung der II. Zone im September 1941 meldeten Garnisonskommandeure, dass die Serben sehr positive Gefühle gegenüber Italien hegten. Insbesondere betonten sie die italienische „humane Gerechtigkeit, die einer höheren Zivilisation geschuldet“ sei. ${ }^{51}$ Die geschilderten, geschickten Maßnahmen seitens der Aufständischen zeigten durchaus Wirkung. Das ging sogar so weit, dass der Befehlshaber des VI. Armeekorps den serbischen Aufstand als „legitime Verteidigung“ klassifizierte. Dies wurde

47 Depesche des Gouverneurs von Dalmatien an den Präsidenten des Ministerrates in Rom, 29.7.1941, abgedr. i. NOB u Dalmaciji, Bd. 1, S. 500-502.

48 ASMAE, GAB-AP 1923-1943, b. 1495, Brief an Mussolini von Milan Prica, 25.7.1941; ASMAE, GAB-AP 1923-1943, b. 1512, Questioni religiose, 23.10.1941; Memoriale dei notabili serbo-ortodossi del distretto di Dervar consegnato al comando del VI corpo d'armata, 23.10.1941, abgedr. i. Talpo: Dalmazia, Bd. 1, S. 996 f.; DAD, T, reg. br. 2207/41, Comando del VI. CdA, Notiziario ${ }^{\circ}$ 105, 16.8.1941.

49 ASMAE, GAB-AP 1923-1943, b. 1493, Notizie pervenute della Dalmazia sulla situazione in Croazia, 22.8.1941; ASMAE, GAB-AP 1923-1943, b. 1497, Lo Stato Maggiore dei distaccamenti di guerriglia in Bosnia, 14.8.1941.

50 ASMAE, GAB-AP 1923-1943, b. 1493, Notizie pervenute della Dalmazia sulla situazione in Croazia, 22.8.1941.

51 AUSSME, N 1-11, DS, b. 524, Diario Storico Divisione Fanteria Marche, Comando di Divisione, Ragusa, Eintrag vom 20.9.1941; AUSSME, N 1-11, DS, b. 543, All. 184, al DS di ottobre 1941, Notiziario Nr. 31, 24.10.1941; AUSSME, N 1-11, DS, b. 543, All. 167, al DS di ottobre 1941, Comando della div. Fant. „RE“, Uff. Affari civili, Relazione, 15.10.1941; ASMAE, GAB-AP 19231943, b. 1495, Rede von Branko Zorčić anlässlich Giuseppe Bastianinis privatem Besuch in Drvar, 18.10.1941. 
unter anderem daran festgemacht, dass die Aufständischen nicht die kroatische Bevölkerung terrorisierten. ${ }^{52}$ Italienische Diplomaten bestätigten die positiven Einstellungen der Serben gegenüber Italien. Sie erinnerten jedoch daran, dass Italien im Moment die einzige Kraft darstellte, die sie beschützen konnte. Ihre Einstellungen könnten sich ändern, wenn die Gefahren für die Serben von kroatischer und deutscher Seite verschwinden würden. ${ }^{53}$

Die Serben schienen der Art des eroberten Volkes zu entsprechen, welches die Diskurse der 1930er Jahre über das italienische Imperium imaginiert hatten: ein Volk, dass die italienische Kultur und Zivilisation schätzte und daher Italiens Führungsrolle anerkannte und gleichzeitig auch die militärische Stärke Italiens würdigte. Dies umso mehr, als der eigentliche Verbündete - das kroatische Volk und die Ustascha - diese Führungsrolle nicht akzeptierte und stattdessen die Deutschen bewunderte. Unter diesen Umständen war jedes Lob über die italienische Armee willkommen. Aus dem Mix von imperialen Vorstellungen, die endlich auf entsprechende Reaktionen stießen, und dem „Wettstreit“ mit den Deutschen darf es wenig überraschen, wenn die italienische Armee bereitwillig eine militärische Allianz mit den (in ihren Augen) Vertretern des serbischen Volkes - den Tschetniks - einging.

In Übereinstimmung mit der deutschen Politik und Propaganda betrieb das Reich keine speziell auf die Serben ausgerichtete Politik. Den Soldaten wurde vielmehr erklärt, dass die Serben „derjenige Volksteil [seien], der dem jungen kroatischen Staate vielfach ablehnend gegenüber steh[e] und Beziehungen zu den feindlichen Kräften im Lande unterh[alte]. “54

Während im italienischen Einflussgebiet im Herbst 1941 die Ustascha entmachtet wurde, geschah nichts Vergleichbares in der deutschen Zone. Dort verübte die Ustascha weiterhin Massaker an der serbischen Bevölkerung wie jenes östlich und südöstlich von Maja am 19. November 1941, bei dem ca. 800 Personen ums Leben kamen. ${ }^{55}$ In dieser Gegend lagen zudem „Tausende und Abertausende von Leichen, die sich durch Ausgrabung ohne weiteres [hätten] identifizieren [lassen]. “ Die Wehrmacht unternahm jedoch nichts desgleichen. ${ }^{56}$ Diese Passivität in Anbetracht des entschlossenen Einschreitens der Italiener in ihrem

52 ASMAE, GAB-AP 1923-1943, b. 1493, Attività anticroata da Serbi a Chistagne, 7.8.1941.

53 ASMAE, GAB-AP 1923-1943, b. 1497, Situazione in Erzegovina, 23.10.1941.

54 BArch, RH 45/45, Merkblatt für deutsche Truppen in Kroatien, ohne Datum, jedoch nach Januar 1943.

55 Im September 1941 wurden sechzig serbisch-orthodoxe Personen, darunter auch Frauen und Kinder, in der Nähe von Sarajevo verbrannt. BArch, RH 31/III/1, Bl. 74, Fernschreiben des Dt. Generals in Agram, 13.9.1941.

56 BArch, RH 31/III/1, Bl. 110, Aufzeichnung für den deutschen Gesandten, 3.12.1941. 
Gebiet, führte zu Gerüchten unter der serbischen Bevölkerung, dass die Ausschreitungen von den Deutschen gewollt waren. ${ }^{57}$ Tatsächlich stellten in den Mental Maps der meisten Deutschen auf dem Balkan die Serben den Feind dar. Die Kroaten waren die Verbündeten, und das Los der orthodoxen Bevölkerung interessierte daher nicht. Das Dritte Reich war an einem funktionierenden kroatischen Staat interessiert, um ihn mit minimalen Kräften am Effektivsten ausbeuten zu können. Deshalb unternahmen deutsche Stellen anfangs nichts, was dessen Führung und somit den gesamten Staat hätte schwächen können.

\subsection{Interaktionen mit der muslimischen Bevölkerung}

Nach der Gründung des Unabhängigen Staates Kroatien befand sich dessen muslimische Bevölkerung nominell in einer besseren Position als im Königreich Jugoslawien,

in which they were subjected to various types of social and economic oppression, to national and cultural inequality, and within which they were often treated as a minority of foreign origin that had no right to their historic identity. ${ }^{58}$

Sie wurden, als „muslimische Kroaten“, den katholischen Kroaten offiziell gleichgestellt und sollten gemeinsam ein „Volk“ bilden. In der Realität des NDH waren die Muslime jedoch weit von der Gleichstellung mit den Kroaten entfernt und mussten unterschiedliche Benachteiligungen hinnehmen. Während die Masse sich neutral verhielt, traten einige Muslime den Ustascha-Formationen bei und verübten Verbrechen an der serbischen Bevölkerung insbesondere in Bosnien. Die Tschetniks rächten sich dafür und die Partisanen warfen ihnen die Unterstützung des NDH vor. ${ }^{59}$ Die Suche nach Überlebensstrategien angesichts dieser Situation sowie Versuche, bosnische und muslimische Autonomie Bosniens zu verteidigen, brachten einen Teil der Muslime dazu, ihre Retter in den Besatzern zu suchen, andere Kooperierten mit den Tschetniks, während sich wieder andere den Partisanen anschlossen. Einige muslimische Politiker unterstützten die Politik des NDH, während andere für eine Autonomie Bosniens plädierten und sich gegen die Ansicht wandten, Muslime seien kroatischen

57 BArch, RW 4/231, Bl. 176, Anlage zum Lagebericht für die Zeit 01.02.-28.02.1942.

58 Redžić, Enver: Bosnia and Herzegovina in the Second World War, London/New York 2005, S. 169.

59 AJ, Fond 110, k. 616, Inv. Br. 16690, Nr. 273-275, Muslime beschweren sich beim NDH, Prijedor, 23.9.1941; Rochas, Amandine: La Handschar. Histoire d'une division de Waffen-SS bosniaque, Paris 2007, S. 25-30. 
Ursprungs. ${ }^{60}$ Die Grenzen zwischen all diesen Gruppen waren, wie so oft, fließend.

Die muslimische geistliche Elite verurteilte jedoch als erste die Verfolgung anderer Ethnien und Religionen im NDH. Bereits im August 1941 verfasste sie die erste „Muslimische Resolution“, in der sie Muslime aufrief, das Leben, die Ehre, das Heim, den Besitz usw. der anderen zu achten und keine Gewalttaten $\mathrm{zu}$ verüben. Gleichzeitig appellierte sie an die Regierung, für Recht und Ordnung zu sorgen. ${ }^{61}$ Die zweite, sogenannte „Sarajevo-Resolution“ vom 18. Oktober 1941, in der die muslimische Elite u. a. die Gleichberechtigung aller im Staat lebenden Personen forderte, verstärkte diesen Appell. In beiden Resolutionen beschwerten sie sich auch darüber, dass von einer echten Gleichberechtigung des Islam mit dem Katholizismus in der Praxis nicht viel spürbar sei, sowie, dass die Verantwortung für den Konflikt mit den Serben auf sie abgewälzt würde. Die Historikerin Nada Kisić Kolanović folgert daraus, dass die Muslime hiermit, weil sie die Regierung in Frage stellten, die Legitimitätskrise des NDH eröffneten. ${ }^{62}$

Neben den Unterzeichnern der Resolutionen sollten autonomistische Kreise innerhalb der Muslime für weitere Instabilität des NDH sorgen. Da die kroatische Armee nicht in der Lage war, die muslimische Bevölkerung vor Übergriffen der Tschetniks zu beschützen, setzte sich ein Teil der Muslime für ein von Kroatien unabhängiges Bosnien unter der Verwaltung einer der Achsenmächte ein. Dabei entwickelten sich zwei Gruppierungen. Diejenigen im deutschen Einflussgebiet suchten für ihre Idee der Autonomie innerhalb des NDH die Hilfe Deutschlands. ${ }^{63}$ Die andere Gruppe wandte sich mit ähnlichen Wünschen an die Italiener. Diese Gruppierungen sollten dann auch den Kern der Zusammenarbeit zwischen den Muslimen und der jeweiligen Besatzungsmacht darstellen.

Das Faschistische Italien hatte seit den 1930er Jahren eine islamfreundliche Politik geführt und sich selbst als Beschützer des Islam dargestellt. Immerhin leb-

60 Redžić: Bosnia and Herzegovina, S. 167 f.; Hoare, Marco Attila: The History of Bosnia from the Middle Ages to the Present Day. London, 2007, 267-273.

61 Kisić Kolanović, Nada: Muslimani i hrvatski nacionalizam 1941-1945, Zagreb 2009, S. 212 f.; Yeshayahu, Jelinek: Bosnia-Herzegovina at War: Relations between Moslems and Non-Moslems, in: Holocaust and Genocide Studies 5 (1990) 3, S. 275-292, hier S. 284 f. Eine weitere „Resolution der Muslime aus Mostar“ ohne Datum, die sich gegen die Verfolgung der Serben wendet, ist abgedruckt in: Zločini Nezavisne Države Hrvatske i nemačkog okupatora u Hercegovini: 1941-1945: Zbornik dokumenata, Bd. 1, Gacko 2011, S. 427 f.

62 Kisić Kolanović: Muslimani i hrvatski nacionalizam, S. 213 f., 354.

63 Im Herbst 1942 wandten sie sich mit einem Memorandum direkt an Hitler. Matković, Hrvoje: Bosansko-hercegovački muslimani u programu ustaške emigracije i politici Nezavisne Države Hrvatske, in: Časopis za suvremenu povijest 38 (2006) 3, S. 1031-1037, hier S. $1035 \mathrm{f}$. 
ten im faschistischen Imperium viele Muslime, die von den Italienern aus politischen Gründen bevorzugt behandelt wurden, wie in Italienisch Ostafrika oder Libyen. ${ }^{64}$ Doch trotzdem entwickelte Italien während der gesamten Besatzung keine eindeutige Strategie für den Umgang mit den Muslimen im NDH. Bis zum Schluss wechselten sich Versuche der Annäherung mit distanziertem Verhalten ab. Darüber hinaus war die italienische Armee durch ihre Unterstützung der Tschetniks an deren Verfolgung der muslimischen Bevölkerung mitverantwortlich. Schon aus den ersten Berichten der italienischen Einheiten geht hervor, dass die Muslime als eine Gruppe wahrgenommen wurden, die sich an den jeweils Stärkeren anlehnte. Weiterhin setzten sich muslimische Führer dafür ein, dass der Sandžak Novi Pazar, ein Gebiet zwischen dem NDH, Serbien und Montenegro, in dem die Mehrheit der Bevölkerung muslimisch war, an den NDH angeschlossen wurde. Dies lief den italienischen Plänen entgegen, die den Verbleib des Gebiets bei Montenegro vorsahen. Zudem geht aus italienischen Berichten hervor, dass sie „die Muslime“ im deutschen - und somit nicht im eigenen - Lager sahen. Angeblich hegten diese großen Respekt für Deutschland, in dem sie den Nachfolger Österreich-Ungarns sahen, das einiges für die Entwicklung der Region unternommen hatte. ${ }^{65}$ Darüber hinaus fand die italienische Armee bald in den Tschetniks ihren wichtigsten Verbündeten. All diese Gründe verhinderten eine rasche Annäherung der Italiener an die muslimische Bevölkerung.

Die als abwartend beschriebene Haltung, mit der ein Abstand zu den Italienern einher ging, gepaart mit der raschen Annäherung der Tschetniks an die Italiener sollten die Muslime im italienischen Besatzungsgebiet teuer bezahlen. Die Exhumierung der serbischen Leichen, welche die Italiener im Herbst 1941 vornahmen, war beispielsweise eine Maßnahme, die vor allem Muslimen schadete. Diese wurde vorwiegend in Ortschaften in der östlichen Herzegowina unternommen, in denen muslimische Ustascha-Einheiten die Serben ermordet hatten. ${ }^{66}$ In den nächsten zwölf Monaten eroberten die Tschetniks viele muslimische Dörfer und nahmen Rache für die von der Ustascha begangenen

64 Arielli, Nir: Fascist Italy and the Middle East, 1933-40, Basingstoke 2010, S. 92-99.

65 ASMAE, GAB-AP 1923-1943, b. 1495, Mussulmani in Bosnia, 15.8.1941. Im Gegensatz zu den meisten Einschätzungen, die den Muslimen abwartende und neutrale Haltung bescheinigten, berichtete der Konsul aus Dubrovnik, dass die antiitalienische Stimmung im Gegensatz zu anderen Ethnien ein konstantes Element unter den Muslimen sei. ASMAE, GAB-AP 1923-1943, b. 1499, Telegramm des Königl. Konsulats in Ragusa an das Außenministerium, 8.11.1941.

66 HDA, OUP, k. 9, Nr. 12825, Mehrere Berichte kroatischer Behörden vom Oktober und November 1941. Viele Ustascha-Einheiten, insbesondere in Ostbosnien, setzten sich aus Muslimen zusammen. 
Taten. Manchmal ging der Terror auch von den MVAC aus. ${ }^{67}$ Dort, wo die Italiener präsent waren, kam ihr im Bando 7 settembre geäußerter Anspruch der Gleichbehandlung aller Bevölkerungsgruppen tatsächlich zur Anwendung: Sie schritten ein und verhinderten Angriffe auf muslimische Städte und Dörfer. ${ }^{68}$ Doch in der Ostherzegowina, wo die meisten Muslime im italienischen Gebiet lebten, ließ die 2. Armee nach dem 7. September 1941 den Tschetniks weitestgehend freie Hand und unterhielt nur in wenigen Städten Garnisonen. So wurde beispielsweise Foča im Dezember 1941 nach dem Abzug der kroatischen Armee von den Italienern, die der Bevölkerung Sicherheit des Lebens und Besitzes garantierten, an die Tschetniks übergeben. Diese ermordeten einem kroatischen Bericht zufolge anschließend ca. 500 Personen. ${ }^{69}$ Für diese Taten war die italienische Armee mitverantwortlich, da sie sie - ähnlich wie das Deutsche Reich die Ustaschagreuel - erst ermöglich hatte.

Die Tschetniks taten ihr Übriges, um die Italiener davon $\mathrm{zu}$ überzeugen, dass die Muslime die Kommunisten unterstützten, und trugen so zur italienischen Skepsis gegenüber dieser Bevölkerungsgruppe bei. ${ }^{70}$ Somit funktionierte die Denunziation der gegnerischen Gruppe(n) in der italienischen Einflusssphäre genauso wie in der deutschen: Der sicherste Weg, jemanden zu kompromittieren war es, ihn der Zusammenarbeit mit Kommunisten zu bezichtigen. So wie die Ustascha generell „Serben“ als Kommunisten darstellte, taten dies die Tschetniks mit „den Muslimen“. Allerdings muss betont werden, dass, damit solche Denunziationen auf fruchtbaren Boden fielen, die Rezipienten bereits entsprechend eingestellt sein mussten. Da die Italiener von vornherein der muslimischen Bevölkerungsgruppe nicht trauten, konnten sie einfach von ihren Beziehungen zu Partisanen überzeugt werden. Andererseits weigerten sich die Italiener im Gegensatz zu den Deutschen hartnäckig, Serben und Kommunisten gleichzusetzen.

67 AUSSME, N 1-11, DS, b. 859, DS 260. Reg. Fant. Murge, Eintrag vom 17.10.1942; ASMAE, GAB-AP 1923-1943, b. 1502, Attività bande anticomuniste, Mostar 21.1.1943.

68 AUSSME, N 1-11, DS, b. 859, 260. Reg. Fant. Murge, DS militare, agosto-ottobre 1942.

69 BArch, RH 31/III/8, Bl. 41, Schreiben des Dt. Konsulats in Sarajevo an die Dt. Gesandtschaft in Zagreb, 6.1.1942. Nach Angaben eines kroatischen Gefangenen wurden in Foča und Goražde 5.000 Personen ermordet. HDA, OUP, k. 12, Nr. 13199, Aussage des Domobranen Očko Dragutin, 29.1.1942.

70 Im Herbst 1941 arbeiteten Partisanen und Tschetniks in Ostbosnien noch weitestgehend zusammen, und so waren die Partisanen mitverantwortlich für die Verbrechen an den Muslimen. Dies trug auch dazu bei, dass die Muslime noch langsamer für den Volksbefreiungskampf gewonnen werden konnten. Vgl. Dedijer, Vladimir: Genocid nad muslimanima, 1941-1945. Zbornik dokumenata i svjedočenja, Sarajevo 1990, S. 67; Tucaković: Srpski zločini, S. 28 f. Auch Mihailović hielt einen Bericht über die Zusammenarbeit zwischen Muslimen und Partisanen im Sommer 1942 für nicht glaubwürdig. Tucaković: Srpski zločini, S. 80. 
Es ist also nicht verwunderlich, dass zunächst etwa ein Jahr verstrich, bis es zu Annäherungen zwischen den Italienern und Muslimen kam. Das geistige Oberhaupt der kroatischen Muslime, Reis-ul-Ulema, hatte zwar im Herbst 1941 die Italiener um Hilfe für die Muslime in Trebinje, das sich in der italienischen zweiten Zone befand, gebeten. Die Italiener analysierten das muslimische Verhalten, boten jedoch keine konkrete Hilfe an. Immerhin kooperierten sie zu dieser Zeit bereits mit den Tschetniks, von welchen die Gefahr für die Muslime ausging. ${ }^{71}$ Anfang 1942 besuchte dann Reis-ul-Ulema den Divisionskommandanten in Mostar, um ihm ein Angebot nicht nur zur Kooperation sondern zur aktiven Agitation im italienischen Sinn - wann und wo Italien es forderte - zu überbringen. Es ist auffällig, dass er ausgerechnet Italien als „die Herrin der Gerechtigkeit und der Zivilisation“ pries. $^{72}$ Wahrscheinlich hatte inzwischen auch er verstanden, für welche Schmeicheleien die Italiener anfällig waren. Nach italienischer Einschätzung hatten sich die Muslime inzwischen sowohl gegenüber den Serben als auch den Kroaten kompromittiert und sahen in der Annäherung an Italien die einzige Überlebensmöglichkeit. Daraufhin kam es zu einer sehr begrenzten militärischen Kooperation. ${ }^{73}$

Im Jahr 1943 setzte sich der Großmufti von Jerusalem wieder bei den Italienern für die bosnischen Muslime ein. Während seiner Bosnienreise ${ }^{74}$ empfing er im italienischen Konsulat in Sarajevo auch eine Delegation der Muslime aus Mostar. Im Anschluss bat er um die Freilassung von 35 von der 2. Armee internierten Muslimen. Doch während die italienischen Behörden noch über den politischen Nutzen eines solchen Schrittes nachdachten, internierte das VI. Armeekorps weitere 50 Personen in Mostar, die meisten von ihnen Muslime. Weitere Beschwerden über das italienische Vorgehen brachten jedoch keinen Erfolg. ${ }^{75}$ Auch für die Italiener gab es Rückschläge: In zwei Ortschaften griffen aus muslimischen Männern zusammengestellte Milizen italienische Truppen an. Eine von Italien aufgestellte und bewaffnete muslimische Miliz lief zu den Partisanen über. ${ }^{76}$

71 ASMAE, GAB-AP 1923-1943, b. 1497, Mussulmani croati, 3.9.1941; ASMAE, GAB-AP 19231943, b. 1493, Reis-ul-Ulema; Situazione dei Mussulmani in Bosnia-Erzegovina e nel Sangiaccato, 16.10.1941; ASMAE, GAB-AP 1923-1943, b. 1497, Situazione in Erzegovina, 23.10.1941. Die Serben hingegen hatten bei der Wahl ihrer Verbündeten keine andere Option als die Italiener. 72 ASMAE, GAB-AP 1923-1943, b. 1512, Notiziario Nr. 280 des VI CdA, 8.2.1942.

73 AUSSME, N 1-11, DS, b. 1264, All. 4, Relazione mensile sul servizio „P“, 5.2.1942. Zur militärischen Kooperation siehe Kap. 7.

74 Er warb für den Eintritt in die bosnische SS-Division.

75 Fabei: Il Gran Mufti, S. 91-96.

76 NARA, T-821, R. 296, Nr. 831, Telespresso 883/100 des italienischen Generalkonsulats in Sarajevo, 3.3.1943. 
Zusammenfassend lässt sich sagen, dass die italienisch-muslimische Annäherung von beiden Seiten nicht gerade mit großem Eifer verfolgt wurde. Aus dem Studium der bosnischen Geschichte glaubten die Italiener herauslesen zu können, dass die Muslime sich jeweils an dem Stärkeren orientierten. Diese vermeintliche „Volkseigenschaft“ trug zu einer gewissen Geringschätzung der kroatischen Muslime bei. Sie sahen sich zu Beginn der Besatzung in ihrem Urteil bestätigt, als sie die muslimische Bevölkerung als distanziert und abwartend wahrnahmen. Die zügige Annäherung der Italiener an die in ihren Augen „ehrlicheren“ Serben verhinderte zudem eine Annäherung an die Muslime, deren Schicksal die italienischen Militärs hinter die militärischen Bedürfnisse zurückstellten. Denn das Erstarken der Tschetniks brachte Gefahren für die muslimische Bevölkerung mit sich.

Am Umgang mit der muslimischen Bevölkerung zeigen sich die Grenzen der italienischen viel proklamierten Politik der Gleichbehandlung aller Personen, die ihren Ursprung im Bando 7 settembre hatte. Diese Politik diente schließlich dem Aufbau des italienischen Imperiums. Lief sie diesem Zweck zuwider, wurde sie kurzerhand ignoriert. Denn die italienischen Generäle waren sich durchaus der Übergriffe durch die Tschetniks gegen die muslimischen Dörfer bewusst. Sie nahmen sie für die Dienste, die ihnen die Tschetniks erwiesen, in Kauf. Die Schuld für die Übergriffe lasteten sie dann gerne dem kroatischen Staat an, der nicht die eigene Bevölkerung beschützen konnte. Doch in diesen Fällen war es ausnahmsweise nicht der kroatische Staat sondern die italienische Armee, die den Schutz in dem von ihr kontrollierten Gebiet hätte sicherstellen sollen.

Zwei unterschiedliche Komponenten bestimmten die deutsche Wahrnehmung der muslimischen Bevölkerung des NDH. Zum Einen betonten muslimische Vertreter die positive Erinnerung an die Zeit österreichischer Herrschaft (18781918) in Bosnien. Ein Teil von ihnen ging sogar so weit, beim deutschen Einmarsch die Errichtung Bosniens als deutsches Reichsland nach dem österreichisch-ungarischen Vorbild $\mathrm{zu}$ fordern. Im Herbst 1942 schickten die Vertreter des autonomistischen Flügels der Muslime ein Memorandum nach Deutschland, in dem sie erneut bosnische Autonomie unter deutschem Protektorat forderten. Dies schmeichelte vor allem den Österreichern unter den deutschen Vertretern, doch wurde die Forderung nach Autonomie abgelehnt. ${ }^{77}$ Sie hätte den NDH geschwächt und daran war das Reich nicht interessiert. Darüber hinaus sahen die Deutschen in den Muslimen den minderwertigeren Teil der kroati-

77 PA-AA, Inland IIg, R. 100.998, Nr. 2574, Waffen-SS: Kroatien, Telegramm des Gesandten Kasche an das Auswärtige Amt, 28.4.1943; Redžić: Bosnia, S. 179 f. 
schen Bevölkerung. Glaise von Horstenau charakterisierte Muslime als „opportunistisch, asozial und rassisch nicht besonders wertvoll“. ${ }^{78}$ Auch das Urteil deutscher Soldaten, als sie mit Muslimen in Berührung kamen, war nicht positiv. Im Brief eines Wehrmachtsoldaten aus Sarajevo vom 18. April 1941 werden die Klischees ganz offen ausgesprochen:

\begin{abstract}
Die Bevölkerung besteht zum großen Teil aus Mohammedanern, die nicht gerade Vertrauen erweckend aussehen. Und diese Elemente haben hier Polizeigewalt. Viel können sie ja damit nicht anfangen. Es bestimmt die Wehrmacht. Aber mit einem Schießprügel über der Schulter und einer Armbinde, neuerdings mit Hakenkreuz, rennen die Brüder umher. Da brauchen sie nur noch rufen „Wir wollen heim ins Reich“. Aber mit den Vagabunden läßt sich bestimmt nichts anfangen. Ich möchte gern wissen, womit die ihren Lebensunterhalt verdienen. Ich glaube mit Stehlen. Morgens bis abends lungern sie in den Strassen umher, entsetzlich zerlumpt. Oder sie sitzen vor einer schmierigen Kaffeestube und schlürfen ihren Mokka. ${ }^{79}$
\end{abstract}

Ein Jahr später fiel auch das Urteil über die muslimischen Soldaten schlecht aus. Sie würden ihren Dienst widerwillig verrichten, sich vom Rest der Truppe absondern und täglich ihre Meinung wechseln. ${ }^{80}$ Auch die Tschetnik-Führer verfolgten aufmerksam die deutsche Einstellung gegenüber den Muslimen. Im August berichteten sie, aus Gesprächen mit deutschen Offizieren den Eindruck gewonnen zu haben, dass die Muslime keine Unterstützung bei den Deutschen erwarten könnten. ${ }^{81}$ Die Muslime rückten erst ins Zentrum des deutschen Interesses, als Anfang 1943 in Berlin die Entscheidung gefallen war, eine kroatische Waffen-SS Division zu bilden. Diese sollte aus Muslimen bestehen.

Noch prekärer als die Absicht, eine muslimische SS-Division zu gründen, war für den kroatischen Staat der Umstand, dass die Deutschen damit die Autonomiebestrebungen unter den bosnischen Muslimen bestärkten. Um bei der Werbung erfolgreich zu sein, versuchten die deutschen Truppen, sich das Wohlwollen der Muslime zu sichern. An die Soldaten der 114. J. D. wurde im April 1943 das Merkblatt „Leitsätze für das Verhalten des Europäers in mohammedanischen Ländern“ verteilt und „zum Gegenstand eingehender Belehrungen“ ge-

78 BArch, RH 31/III/1, Bl. 124, Glaise von Horstenaus Bericht: „Die Lage in Kroatien Mitte Dezember 1941“.

79 Franz S. an seine Eltern am 18.4.1941 (3.2002.1285). <http://www.museumsstiftung.de/briefsammlung/feldpost-zweiter-weltkrieg/brief.html?action=detail\&what=letter\&id=626> (18.3.2019).

80 BArch, RH 26/114/16, I. Batl. 9. Inf. Regt, Ursache des Nachlassens des Kampfgeistes der Truppe, 23.12.1942. Der von einem Kroaten geschriebene Bericht wurde von seinem deutschen Vorgesetzten als zutreffend bestätigt.

81 Befehl des Kommandeurs der Tschetnikbrigade Majevica, die Durchfahrt einer deutschen Kolonne zu sichern, 27.8.1942, abgedr. i. Zbornik, XIV/1, Nr. 154, S. 571 f. 
macht. Die Leitsätze erklärten die Gleichberechtigung der Religionen und forderten die Soldaten dazu auf, bestimmte Regeln im Umgang mit Muslimen einzuhalten. Dazu gehörten die Achtung vor der Verrichtung des Gebets, kein gewaltsames Eindringen in Moscheen, der Aufbau guter Beziehungen zu Hadjis, der Hinweis, den Bettlern Spenden zu geben, sowie das Unterlassen jeglicher Versuche, Kontakte zu moslemischen Frauen zu knüpfen. Sich darauf beziehend wurde auch bei der Besetzung des Sandžaks ein vorbildliches Verhalten gegenüber den Muslimen angemahnt. ${ }^{82}$ Einige der Muslime nutzten die deutsche Aufmerksamkeit, um ihre Unzufriedenheit mit dem kroatischen Staat zu demonstrieren. So beklagte sich der Bürgermeister von Sarajevo, dass Zagreb Bosnien weder regieren könne noch wolle, und deshalb eine Neugestaltung des Staates nötig sei. In Bosnien habe man den Eindruck, in Zagreb wollte man durch die Herrschaft der Ustascha die Serben und die Muslime gegeneinander ausspielen. Mit der Schaffung der SS-Division würde aber nun eine deutliche Grenze zwischen Kroatien und Bosnien gezogen, die dafür ausgenutzt werden sollte, eine bosnische Autonomie einzusetzen. Daher verwundert es nicht, dass insbesondere die „Autonomisten“ den Deutschen bei der Aufstellung der SS-Division halfen. ${ }^{83}$ Dies trug zumindest in der Werbepropaganda Früchte, da auf einigen deutschen Flugblättern tatsächlich auch auf die Autonomiebestrebungen eingegangen wurde. Auch der Besuch des Großmuftis von Jerusalem bestärkte die „Autonomisten“ in ihren Bestrebungen und führte zu weiteren Konflikten zwischen Deutschland und dem $\mathrm{NDH}^{84}$ Doch hier erwiesen sich kroatische Befürchtungen als unbegründet: Die Elite des Reichs war an einem Fortbestehen des NDH interessiert und unterstützte die autonomistischen Bestrebungen nur so weit, wie sie ihr für die Aufstellung der „Handschar“ Division dienten.

Beide Besatzer hatten im Vergleich relativ wenig Kontakt zur muslimischen Bevölkerung. Für die italienische Besatzung zeigt der Blick auf deren Umgang mit

82 BArch, RH 26/114/19, Merkblatt „Leitsätze für das Verhalten des Europäers in mohammedanischen Ländern“, 11.4.1943; Befehl des Kommandierenden Generals und Befehlshabers in Serbien vom 25.4.1943, abgedr. i. Zbornik, XII/3, Nr. 55, S. 239-244.

83 PA-AA, Inland IIg, R. 100.998, Nr. 2575, Waffen-SS: Kroatien, Telegramm des Gesandten Kasche an das Auswärtige Amt, 9.6.1943; PA-AA, Inland IIg, R. 100.998, Nr. 2574, WaffenSS: Kroatien, Telegramm des Gesandten Kasche an das Auswärtige Amt, 28.4.1943. Die Autonomistische Bewegung entstand 1939 während der Verwaltungsreform des jugoslawischen Staates. Am 1. September 1942 verfassten ihre Vertreter ein Memorandum an Adolf Hitler, in dem sie um die Autonomie Bosniens unter dem Deutschen Reich baten. Kisić Kolanović: Muslimani i hrvatski nacionalizam, S. 323, 332.

84 Kisić Kolanović: Muslimani i hrvatski nacionalizam, S. 367-369. 
den Muslimen die Grenzen der von der italienischen Armee stets verkündeten Gleichbehandlung aller Bevölkerungsgruppen. Dies wiederum unterstreicht die politische Komponente dieser Politik. Die Zurückhaltung der Deutschen war mit ihrem gesamten Auftreten im NDH konsistent. Sie versuchten diese Gruppe für ihre Ziele $\mathrm{zu}$ benutzen, die Bindung an die Ustascha hatte jedoch stets Vorrang und durfte nicht gefährdet werden. Schließlich fällt auf, dass beide Besatzer bestimmte orientalistisch anmutende Vorurteile gegenüber den als „fremd“ wahrgenommenen Muslimen des NDH bereits mit sich brachten, wonach diese in erster Linie Opportunisten seien, denen man nicht trauen könne. ${ }^{85}$

\subsection{Das Deutsche Reich und die Volksdeutschen}

Der „Unabhängige Staat Kroatien“ war die Heimat von ca. 170.000 Volksdeutschen, die vornehmlich im Norden des Landes, Ostslawonien und Syrmien und $\mathrm{zu}$ einem geringeren Teil in Siedlungen in Nordbosnien lebten. ${ }^{86} \mathrm{Im}$ Rahmen des „Generalplans Ost“ sollten sie nach dem Krieg aus Kroatien ausgesiedelt und in den neuerworbenen Gebieten im Osten angesiedelt werden. Aufgrund der steigenden Partisanenangriffe wurde mit der Umsiedlung der verstreut lebenden Deutschen in Bosnien und Südwestkroatien jedoch bereits im Sommer 1941 begonnen. ${ }^{87}$ In der Zwischenzeit bekamen die Volksdeutschen einen besonderen Status in Kroatien. Das „Dekret zum vorläufigen Rechtsstatus der

85 Zum Orientalismus grundlegend: Said, Edward: Orientalismus, Frankfurt am Main 1981. Franziska Zaugg hat in ihrer Untersuchung der albanischen SS-Division „Skanderbeg“ auf ein ähnlich „exotisches“ Bild der Albaner hingewiesen. Zaugg, Franziska: Albanische Muslime in der Waffen-SS. Von „Großalbanien“ zur Division „Skanderbeg“, Paderborn 2016, insb. S. 293-310.

86 Jareb, Mario: The German Ethnic Group in the Independent State of Croatia (Deutsche Volksgruppe in Kroatien) from 1941 to 1945, in: Review of Croatian History (2007) 1, S. 201217, hier S. 202. Zur deutschen Volksgruppe in Kroatien vor dem Krieg siehe Bethke, Carl: Deutsche und ungarische Minderheiten in Kroatien und der Vojvodina 1918-1941. Identitätsentwürfe und ethnopolitische Mobilisierung, Wiesbaden 2009.

87 Aufzeichnung des vortragenden Legationsrats Großkopf, 7.8.1941, abgedr. i. ADAP, D, XIII/ 1, Nr. 187, S. 244 f. PA-AA, StS Kroatien, Bd. 3, R. 29.667, Nr. 688, Nr. 331 f., Telegramm des Volksgruppenführers Altgeyer an das Auswärtige Amt, 23.9.1942. Insgesamt wurden 18.000 Personen aus Bosnien umgesiedelt, sowie weitere 12.000 aus den Gebieten nördlich der Save. Bethke, Carl: Von der „Umsiedlung“ zur „Aussiedlung“. Zur destruktiven Dynamik „ethnischer Flurbereinigung“ am Beispiel der Deutschen in Bosnien und Kroatien 1941-1948, in: Hausleitner, Mariana (Hg.): Vom Faschismus zum Stalinismus. Deutsche und andere Minderheiten in Ostmittel- und Südosteuropa 1941-1953, München 2008, S. 23-39, hier S. 29.

Casagrande, Thomas: Die Volksdeutsche SS-Division „Prinz Eugen“. Die Banater Schwaben und die nationalsozialistischen Kriegsverbrechen, Frankfurt/New York 2003, S. 250. 
deutschen ethnischen Gruppe im Unabhängigen Staat Kroatien“ vom 21. Juni 1941 garantierte ihnen dieselben Rechte wie dem kroatischen Volk. Darüber hinaus wurde die deutsche Volksgruppe zum integralen Teil des NDH erklärt, jedoch mit weitreichenden Autonomierechten. Im Gegenzug erkannte sie formal den NDH an. Dieses und weitere Dekrete und Gesetze erlaubten es der Volksgruppe, das Leben ihrer Mitglieder politisch, kulturell, ökonomisch und sogar militärisch selbst zu organisieren. So wurde der landwirtschaftliche Sektor nach dem deutschen Vorbild (Reichsnährstand) umgebaut und die Volksgruppe sollte ihre Erzeugung an die Bedürfnisse des Reichs anpassen. ${ }^{88}$ Dies war auf einer Linie mit der deutschen Politik gegenüber Südosteuropa, das einen wirtschaftlichen Ergänzungsraum, insbesondere auch für Agrarprodukte, bilden sollte.

Die Italiener verfolgten die Volksdeutschengesetzgebung sehr genau. Insbesondere störten sie sich an der Vereidigung auf Hitler, der unklaren Festlegung der Volkszugehörigkeit sowie der Bindung der Volksdeutschen ans Reich. Nach Pietromarchis Auffassung konnten die Deutschen die kroatische Souveränität nicht wahren, wenn sie solche Gesetze forderten. Ähnlich äußerten sich auch Coselschi und Casertano. ${ }^{89}$ Da die deutschen Stellen in dieser Sache jedoch nicht nachgaben, mussten sie sich mit der Situation abfinden.

Während die deutsche Volksgruppe also vom kroatischen Staat weitgehende Autonomie besaß, unterstand sie in erster Linie der Volksdeutschen Mittelstelle (VoMi), einem Hauptamt der SS in Berlin, das für alle Volksdeutschen auBerhalb des Reichs zuständig war. Bald dominierten reichsdeutsche Interessen die Behandlung der Volksgruppe, die in erster Linie einen Beitrag zum Krieg liefern sollte. Darunter verstand man vor allem „Menschenmaterial“, aber die Volksdeutschen waren auch für den deutschen Geheimdienst sehr wertvoll. Mehr als 15.000 Volksdeutsche sollten unter Konstantin Kammerhofer für die deutsche Polizei arbeiten. ${ }^{90}$ Dabei kämpften unterschiedliche deutsche Stellen

88 Krnić, Zdravko: Položaj Njemačke narodne skupine u Nezavisnoj Državi Hrvatskoj, in: Zbornik centra za društvena istraživanja Slavonije i Baranje 21 (1984) 1, S. 205-239, hier, S. 218-233; Calic, Marie-Janine: Die Deutsche Volksgruppe im „Unabhängigen Staat Kroatien“ 1941-1944, in: Hausleitner, Mariana (Hg.): Vom Faschismus zum Stalinismus. Deutsche und andere Minderheiten in Ostmittel- und Südosteuropa 1941-1953, München 2008, S. 11-22, hier S. $16 \mathrm{f}$.

89 PA-AA, Inland IIg, R. 101.092, Nr. 2815, Bericht und Meldungen zur Lage in Jugoslawien; PA-AA, Inland IIg, R. 101.092, Nr. 2816, Telegramm des Gesandten Kasche an das Auswärtige Amt, 14.11.1941; PA-AA, Inland IIg, R. 100.942, Nr. 2430, Anlage 7 zum Bericht der Gesandtschaft in Zagreb, 16.1.1942.

90 Sundhaussen, Holm: Zur Geschichte der Waffen-SS in Kroatien 1941-1945, in: Südost-Forschungen 30 (1971), S. 176-196, hier S. 179; Krnić, Zdravko: The German Volksgruppe in the Independent State of Croatia as an Instrument of German Occupation Policy in Yugoslavia, in: The Third Reich and Yugoslavia 1933-1945, hgg. v. Institute for Contemporary History, Belgrad 1977, S. 604-621, hier S. 616. 
um die Volksdeutschen. Auf der einen Seite stand Himmler mit seinen Untergebenen Lorenz und Berger, der sie alle für die Waffen-SS vereinnahmen wollte, auf der anderen Seite versuchte Kasche (unterstützt durch Unterstaatssekretär Luther und teilweise Ribbentrop), die Volksdeutschen in Kroatien bei der kroatischen Armee oder der deutschen Wehrmacht $\mathrm{zu}$ belassen. Letztlich konnte sich die SS durchsetzen, da einerseits Anfang 1943 Kasches größter Fürsprecher im Auswärtigen Amt, Martin Luther, entlassen wurde, und andererseits der Ausbau der Waffen-SS für Hitlers Politik sich als deutlich effektiver erwies als der Beitrag der bald machtlosen kroatischen Regierung. ${ }^{91}$

Die privilegierte Behandlung der Volksdeutschen, die ansonsten nur der Ustascha vorbehalten war, führte in der täglichen Anwendung der Gesetze schon bald zu Schwierigkeiten zwischen den Kroaten und den Volksdeutschen. Dies wirkte sich ebenfalls negativ sowohl auf das Ansehen der Deutschen in Kroatien, als auch auf die Zusammenarbeit zwischen kroatischen Behörden und deutschen Stellen aus. In einem Punkt arbeiteten die Vertreter der Volksdeutschen und die Ustascha jedoch gut zusammen: bei der Verfolgung der jüdischen Bevölkerung Kroatiens. Bereits im Mai 1941 organisierten sie gemeinsam in einigen kroatischen Städten die sogenannten Kontributionszahlungen. Dabei erpressten sie die Vertreter der jüdischen Gemeinde der jeweiligen Stadt, einen von ihnen festgesetzten Betrag zu zahlen, während sie ihnen im Gegenzug oft Schutz für die jüdischen Bürger der Stadt versprachen. ${ }^{92}$ Dieses Versprechen hielten sie nicht. Nach diesen ersten und unkoordinierten Raubzügen einigte sich die Vertretung der Volksdeutschen Kroatiens im Frühjahr 1942 ganz offiziell mit der kroatischen Regierung, wie die Verteilung des geraubten jüdischen Besitzes stattfinden sollte, damit die Volksdeutschen hierbei nicht benachteiligt wurden. ${ }^{93}$ Gleichzeitig waren Vertreter der Volksdeutschen auch am kroatischen System der Konzentrationslager beteiligt. Die Wachmannschaften und auch der Kommandant des Konzentrationslagers Loborgrad, Karlo Heger, gehörten zur deutschen Volksgruppe. ${ }^{94}$

91 Vgl. Sundhaussen: Zur Geschichte der Waffen-SS in Kroatien, S. $190 \mathrm{f}$.

92 Protokoll einer Besprechung im Ustascha-Präsidium in Vukovar, Anf. Mai 1941, abgedr. i. Heim, Susanne/Herbert, Ulrich/Hollmann, Michael u. a. (Hg.): Die Verfolgung und Ermordung der europäischen Juden durch das nationalsozialistische Deutschland 1933-1945, Bd. 14: Besetztes Südosteuropa und Italien, München 2017 (VEJ 14), Dok. 90, S. 341 f.; Bethke, Carl: (K)eine gemeinsame Sprache? Aspekte deutsch-jüdischer Beziehungsgeschichte in Slawonien, Leipzig 2011, S. 260-267.

93 Vermerk des Hauptamtsleiters der Volksgruppenführung der Deutschen in Kroatien, 30.3.1942, abgedr. i. VEJ 14, Dok. 147, S. 434-436.

94 Bethke, Carl: Das Frauen und Kinderkonzentrationslager Loborgrad in Kroatien (19411942), in: Geiger, Vladimir/Grahek Ravančić, Martina/Karakaš Obradov, Marica (Hg.): Logori, 


\subsection{Die Verfolgung der jüdischen Bevölkerung}

Das Schicksal der jüdischen Bevölkerung des NDH, die 1941 schätzungsweise 40.000 Personen zählte, stellte sich anders als das der anderen Minderheiten dar. ${ }^{95}$ Obwohl die Ustascha in den Serben den wichtigsten Feind sah, ging sie von Anfang an auch gegen die Juden vor. Im Kampf um die eigene Unabhängigkeit hatte die Ustascha bald erkannt, dass der kroatische Staat nur an deutscher Seite eine Zukunft hatte. Sie hoffte, vom Reich besser behandelt zu werden und ihre territorialen Aspirationen befriedigen zu können, wenn sie sich als „treuer“ und „fähiger“ als andere deutsche Verbündeten erwies. ${ }^{96}$ Dazu gehörte auch die Judenverfolgung nach deutschem Vorbild. Bereits am 22. April verkündete Innenminister Andrija Artuković, dass die Regierung die „Judenfrage bald auf dieselbe Art lösen [würde], wie die deutsche Regierung sie gelöst" habe. ${ }^{97}$ Der neue Staat erließ sofort antijüdische Gesetze, die sich an denjenigen des nationalsozialistischen Deutschlands orientierten. Doch parallel wurden viel härtere Maßnahmen durch lokale Behörden, Polizeiorgane und einzelne Ustascha durchgeführt. ${ }^{98}$ Sie verhafteten zunächst angesehene oder auch junge jüdische Männer und deportierten sie in Lager, die ad hoc gebildet wurden und sich spätestens im Sommer verfestigten, als das zentrale Lager Jasenovac eingerichtet wurde. Die Ermordungen der Lagerinsassen setzten bereits im Frühling ein. Die Verfolgung der Juden (und Roma) intensivierte sich noch, nachdem die Serbenverfolgung bei den Deutschen Unmut ausgelöst hatte. ${ }^{99}$ Weitestgehend verschont blieben wie im Deutschen Reich Juden und Jüdinnen in Mischehen so-

zatvori i prisilni rad u Hrvatskoj / Jugoslaviji 1941-1945, 1945-1951. Zbornik radova, Zagreb 2010, S. 57-72.

95 Zahlenangabe nach Sundhaussen, Holm: Jugoslawien, in: Benz, Wolfgang (Hg.): Dimension des Völkermords, München 1991, S. 311-330, hier S. 313.

96 Vgl. Bartulin: The NDH as a „Central European Bulwark against Italian Imperialism“, S. 59.

97 „Wir warnen!“, in: Deutsche Zeitung in Kroatien, 22.4.1941, S. 1.

98 Verordnung mit Gesetzeskraft über die Rassenzugehörigkeit, Verordnung mit Gesetzeskraft über den Schutz des arischen Blutes und der Ehre des kroatischen Volkes, abgedr. i. VEJ 14, Dok. 88 und 89, S. 338-341; Rosenberg: Dragutin: Bericht über die Lage der Juden in Jugoslawien 1941-1943, in: Levental, Zdenko: Auf glühendem Boden. Ein jüdisches Überlebensschicksal in Jugoslawien 1941-1947, hgg. v. Erhard Roy Wiehn/Jacques Picard, Konstanz 1994, S. 215257, hier S. 220.

99 Korb, Alexander: Nation-building and Mass Violence. The Independent State of Croatia, 1941-45, in: Friedman, Jonathan C. (Hg.): The Routledge History of the Holocaust, London/ New York 2011, S. 291-302, hier S. 296, 298 f.; Bilandžić, Dušan: Hrvatska moderna povijest, Zagreb 1999, S. 125. 
wie Halbjuden. ${ }^{100}$ Eine genuin kroatische Handlungsweise stellte die Ausnahme all derjenigen Juden dar, denen „Arierrechte“ zuerkannt worden waren. Doch umfasste diese Gruppe insgesamt nur ca. 500 Personen. ${ }^{101}$ Schließlich versuchte die katholische Kirche die zum Katholizismus konvertierten Juden zu schützen mit nur mäßigem Erfolg.

Die „Lösung der Judenfrage“ war einer der zentralsten Punkte der nationalsozialistischen Herrschaft, nicht nur in Deutschland, sondern in ganz Europa. ${ }^{102}$ Aus der Verfolgung der eigenen Pläne und Ziele, der Orientierung am Deutschen Reich in der Frage der rassischen Komposition des Staates sowie der allgemeinen Abhängigkeit vom Reich verschrieb sich die Ustascha sofort diesem Ziel. Das konnte Deutschland nur begrüßen. Daher muss es nicht unbedingt verwundern, dass sich für die erste Phase der Judenverfolgung im NDH eine deutsche Komplizenschaft in den überlieferten Quellen nicht nachweisen lässt, wenn auch davon auszugehen ist, dass es sie gegeben hat. Die Sipo durchsuchte immerhin bereits einen Tag nach dem Einmarsch der Wehrmacht und der Ausrufung des NDH die Geschäftsräume der Jüdischen Gemeinde Zagreb und versiegelte deren Finanzen. ${ }^{103} \mathrm{Da}$ in den ersten Wochen des NDH vieles inoffiziell über deutsche Berater bei der Ustascha initiiert bzw. gesteuert wurde, fielen die antijüdischen Maßnahmen sicherlich hierunter. Die Ähnlichkeit der drei antijüdischen Gesetzesdekrete, die bereits am 30. April 1941 verabschiedet wurden, zu den Nürnberger Gesetzen indiziert diesen Umstand. Belegt ist weiterhin, dass sich die kroatische Regierung im Herbst des Jahres an das Deutsche Reich mit Detailfragen zur Judenverfolgung wandte. Sie wollte wissen, welche Rechte diejenigen Juden hatten, die im Reich geblieben waren und wie sie sich in der Wirtschaft betätigen durften, da sie die „Judenfrage“ ähnlich wie in Deutschland lösen wollte. ${ }^{104}$

100 Zur Verfolgung dieser Gruppen in Deutschland siehe: Hilberg, Raul: Die Vernichtung der europäischen Juden, Bd. 2, Frankfurt am Main 2007, S. 436-449.

101 Auch wenn die Mehrheit dieser Personen den Krieg überlebte, wurden auch sie zu Opfern von Verfolgung. Goldstein/Goldstein: Holokaust u Zagrebu, S. 378.

102 Vgl. Gerlach, Christian: The Wannsee Conference, the Fate of German Jews, and Hitler's decision in Principle to Exterminate All European Jews, in: The Journal of Modern History, 70 (1998) 4, S. 759-812, hier S. 784-790. Gerlach betont, dass es sich bei Hitlers Ankündigung im Dezember 1941 nicht um eine konkrete Direktive, sondern um eine grundsätzliche Entscheidung handelte. Die praktische Implementierung, die Organisation und das Tempo sollten durch die zuständigen Ämter bestimmt werden.

103 HDA, ZKRZ-GUZ, roll Z-2944 (ZM 22/11), Bericht über die Durchsuchung in der Jüdischen Kultusgemeinde Zagreb, 11.4.1941.

104 Schreiben aus dem Büro des kroatischen Staatsführers an die dt. Gesandtschaft, 29.9.1941, abgedr. i. VEJ 14, Dok. 113, S. 376. 
Anfang 1942 befanden sich die meisten jüdischen Bürger Kroatiens, wenn sie nicht bereits ermordet worden oder geflohen waren, in kroatischen Lagern. An diesem Punkt war, wie der Innenminister bei der einzigen Sitzung des kroatischen Reichstags vom Februar 1942 verkündete, für die Ustascha die „Judenfrage gelöst““ ${ }^{105}$ Doch dieses Resultat stellte die Deutschen nicht zufrieden. In einem Bericht an das Reich vom Mai 1942 hieß es, dass sich noch genug Juden retten konnten. Daraufhin wurde die kroatische Regierung darüber informiert, dass die Deutschen die „Umsiedlung“ der restlichen Juden planten. Um die „gründliche“ Durchführung der Aktionen zu garantieren, reiste Hans Abromeit von der Abteilung IV B im RSHA nach Zagreb. Er sollte dem Polizeiattaché Hans Helm in dieser Angelegenheit zur Seite stehen. Abromeits Ankunft setze die Ustascha-Bürokratie unter Druck, die Erfassung und die Deportation der Juden zu verbessern. Tatsächlich lief die daraufhin im August einsetzende Verhaftungsund Deportationswelle, bei der nach SS-Angaben 4.972 Juden nach Auschwitz abtransportiert wurden, deutlich geplanter ab. Den zu deportierenden Juden wurde nun die kroatische Staatsangehörigkeit aberkannt, während ihr Vermögen dem Staat, dessen Angehörige sie nicht mehr waren, zufiel. Für den Abtransport eines jeden Juden zahlte der NDH 30 RM an das Reich. ${ }^{106}$

In Zagreb blieb noch ein kleiner Rest der einstigen jüdischen Gemeinde übrig, der sich durch persönliche Verbindungen, Interventionen und die Anwesenheit von Diplomaten und Vertretern anderer internationaler Organisationen retten konnte. Um auch diese Juden zu deportieren, planten die deutschen Stellen Anfang 1943 in Zusammenarbeit mit der Ustascha eine letzte Aktion. Da die Ustascha jedoch bereits damit überfordert war, die Aufenthaltsorte der sich noch in Freiheit befindenden Juden zu bestimmen, involvierte Hans Helm die Volksdeutschen in diese Aufgabe. Die Ortsführer sollten ihm melden, ob und

105 Goldstein: Judengenozid, S. 327 f. Im Frühjahr wurde gar eine antisemitische Ausstellung organisiert, deren Hauptaussage war, dass die „Judenfrage gelöst“ sei. Goldstein/Goldstein: Holokaust u Zagrebu, S. 408-411.

106 Holm Sundhaussen sieht im Verlust der Staatsbürgerschaft (eigentlich der Staatsangehörigkeit, denn Staatsbürger waren sie bereits nicht mehr) eine Maßnahme, mit der die kroatische Scheinselbständigkeit gewahrt werden sollte. Doch verloren auch deutsche Juden ihre Staatsangehörigkeit vor der Deportation. Gleichzeitig fiel ihr Vermögen dem Deutschen Reich zu. So hat es sich wahrscheinlich um eine „Routinemaßnahme“ gehandelt. Gottwaldt, Alfred/Schulle, Diana: Die „Judendeportationen“ aus dem Deutschen Reich 1941-1945: Eine kommentierte Chronologie, Wiesbaden 2005, S. 45 f.; Sundhaussen: Jugoslawien, S. 323; Fernschreiben des RSHA IV b 4a an den Polizeiattaché bei der Dt. Gesandtschaft in Kroatien, 7.8.1942, abgedr. i. VEJ 14, Dok. 157, S. 449; PA-AA, R. 100.942, Nr. 2430, Telegramm des Gesandten Kasche an das RSHA, 16.10.1942. 
wie viele Juden sich noch in ihren Gemeinden aufhielten. ${ }^{107}$ Im Mai 1943 wurden schließlich die restlichen 1.700 Zagreber Juden und 300 Juden, die in anderen Ortschaften identifiziert werden konnten, im letzten Transport aus dem NDH nach Auschwitz verbracht. ${ }^{108}$

Die Gründlichkeit, mit der die Deutschen die „Lösung der Judenfrage“ betrieben, wird besonders deutlich, wenn man bedenkt, dass sie im Sommer 1943 ebenfalls versuchten, der wenigen hundert Juden, die sich vor den Verfolgungen retten konnten, habhaft zu werden. Diesmal konnten sie aber ihre Mission nicht erfüllen, da diese entweder von hohen Ustascha-Funktionären geschützt, oder aber vom kroatischen Staat gebraucht wurden. ${ }^{109}$ Ebenso versuchten die Deutschen alle Juden, die sich in die italienische Besatzungszone geflüchtet hatten, zu deportieren, wie weiter unten eingehender beschrieben wird. Nach der italienischen Kapitulation gelang es ihnen, einige dieser Personen zu verhaften, die sie entweder ermordeten oder in die Lager deportierten. ${ }^{110}$ Nach diesen letzten Aktionen beurteilte auch die deutsche Gesandtschaft Kroatien als „im weitesten Maße bereinigt“. .111

In dem von der italienischen Armee besetzten Gebiet gestaltete sich die Situation völlig anders. Im Zusammenhang mit dem Aufbau eines explizit faschistischen Images, das sich sowohl von dem nationalsozialistischen, als auch dem Ustascha-Bild unterschied, propagierten die Italiener eine Gleichbehandlung aller Personen. Als die Militär- und Zivilgewalt im NDH mit den Römischen Protokollen an die Kroaten übergegangen war, kam dieses Prinzip nur noch im italienischen Teil Dalmatiens zur Anwendung. Auf kroatischem Gebiet hatten italienische Soldaten die Anweisung, sich aus kroatischen Angelegenheiten herauszuhalten. Viele Juden versuchten daher, sich vor den Verfolgungen in das von Italien annektierte Gebiet zu retten. Erste Meldungen über flüchtende Juden

107 HDA, 1521, Hans Helm, k. 37, Buch XX, S. 80, 82, 88.

108 Goldstein/Goldstein: Holokaust u Zagrebu, S. 465-471; Sundhaussen: Jugoslawien, S. 326. Tomislav Dulić hat nachgewiesen, dass 95\% der ermordeten Juden aus dem NDH in Konzentrationslagern getötet wurden. Darunter befinden sich auch deutsche Konzentrationslager, in welchen ca. 8.000 Juden aus dem NDH ermordet wurden. Dulić: Mass killing, S. $271 \mathrm{f}$.

109 Chef der Sicherheitspolizei und des SD an das Auswärtige Amt, 13.7.1943, in: VEJ 14, Dok. 189, S. 500 f. Siehe auch Kestler, Stefan: Hitler, Ante Pavelic und der „Unabhängige Staat Kroatien“. Anmerkungen zu Totalitarismus, Verfolgung und Massenmord in Südosteuropa 1941-1945, in: Aufklärung und Kritik. Zeitschrift für freies Denken und humanistische Philosophie, 4 (1997) 2, S. 118-135, hier S. 126; Sundhaussen: Jugoslawien, S. 326.

110 Birn, Ruth Bettina: Austrian Higher SS and Police Leaders and Their Participation in the Holocaust in the Balkans, in: Holocaust and Genocide Studies 6 (1991) 4, S. 351-372, hier S. 361. 111 Der Gesandte Kasche an das Auswärtige Amt, 22.4.1944, abgedr. i. ADAP, Serie E, Bd. VII, Göttingen 1979, Dok. 352, S. 658 f.; Vgl. auch VEJ 14, Einleitung, S. 49 f. 
(und Serben) wurden bereits im Mai 1941 verfasst sowie ihre Konfinierung in Italien oder auf einer der dalmatinischen Inseln vorgeschlagen. ${ }^{112}$

Die Italiener waren über die ersten antijüdischen Maßnahmen der deutschen Besatzer in Serbien, informiert. ${ }^{113}$ Sie wussten auch, dass die Juden von den Kroaten verhaftet und in Lager gebracht wurden - erste Lager befanden sich im italienischen Einflussgebiet. So war auf der Insel Pag die italienische Garnison 6 Kilometer vom kroatischen Lager entfernt stationiert, wo zahlreiche Serben und Juden von Juni bis August 1941 auf brutalste Weise getötet wurden. Das Morden wurde im August 1941 beendet und das Lager aufgelöst, als der Ustascha klar wurde, dass die Italiener in der II. Zone, in der auch die Insel lag, die Macht übernehmen würden. Diese bargen im Anschluss 791 Leichen und verbrannten sie aus hygienischen Gründen. Doch die Zahl der Getöteten war noch deutlich höher, da die Ustascha viele Leichen ins Meer geworfen hatte. ${ }^{114}$ Die italienische Armee fertigte einen Bericht an, der die an Juden und Serben begangenen Gräueltaten festhielt und nicht nur in den Militärkreisen, sondern auch beim Königshaus, bei Funktionären in Rom und bei der Kirche zirkulierte. ${ }^{115}$

Auch wenn die italienischen Soldaten bis September 1941 nicht befugt waren, sich in die inneren Angelegenheiten des NDH einzumischen, so schmuggelten sie und auch kroatische Staatsangehörige Juden auf italienisches Gebiet. Die Armeeposten ließen vielmals die Flüchtlinge - gegen Schmiergeld, ${ }^{116}$ weil die Durchlassscheine nicht richtig kontrolliert wurden oder aus Hilfsbereitschaft - ihr Gebiet betreten. Manchmal wurden die Flüchtlinge aber auch an der Grenze aufgehalten oder wieder zurück geschickt. ${ }^{117}$ Noch im Frühjahr 1943

112 AUSSME, N 1-11, DS, b. 580, rac. 52, Nr. 6, Immigrazione in Dalmazia di serbo-ortodossi ed ebrei, 24.5.1941.

113 NARA, T-821, R. 233, Nr. 156, Relazione Settimanale, 25.7.1941; ASMAE, AP, JU 1941, b. 106, fasc. 1c, Carte Jugoslave, Disposizioni per gli ebrei, 26.6.1941.

114 The Crimes of the Fascist Occupants and their Collaborators Against Jews in Yugoslavia, hgg. v. Federation of Jewish Communities of the Federative People's Republic of Yugoslavia, Belgrad 1957, S. 124 f., 130.

115 Shelah: Un debito di gratitudine, S. 46 f. Menachem Shelah hält diesen Bericht, den viele einflussreiche Personen gesehen hatten, für entscheidend für das anschließende italienische Verhalten gegenüber den Juden.

116 Die Deutschen meldeten, der Schmuggel würde zwischen 10.000 und 50.000 Kuna kosten. BArch, RH 31/III/8, Mitteilung des deutschen Oberleutnant Weis, 22.12.1941.

117 ASMAE, GAB-AP 1923-1943, b. 1511, Appunto Nr. 5, ohne Datum; AUSSME, N 1-11, DS, b. 580, rac. 53, Nr. 3, Comando VI CdA, 25.5.1941; AUSSME, N 1-11, DS, b. 449, All. 55, Tentativi di emigrazione clandestina di ebrei in territorio annesso, 12.8.1941; Loker, Zvi: The Testimony of Dr. Edo Neufeld: The Italians and Jews in Croatia, in: Holocaust and Genocide Studies, 7 (1993) 1, S. 67-76; Bon, Silva: Le Comunità ebraiche della Provincia italiana del Carnaro: Fiume 
gab das Kommando der 2. Armee eine Anweisung, weitere Juden, die versuchen würden, in den italienischen Bereich zu kommen, „ohne weiteres“ abzuweisen. ${ }^{118}$ Trotz dieser Schwierigkeiten siedelten ca. 4.000-5.000 Juden auf das von Italien kontrollierte Gebiet über. ${ }^{119}$

Bereits im Dezember 1940 hatte das italienische Innenministerium alle Präfekten der Grenzprovinzen darüber informiert, dass ausländischen Juden nicht erlaubt war, Italien zu betreten. ${ }^{120}$ Die Haltung der italienischen Behörden gegenüber den flüchtenden Juden war jedoch widersprüchlich und unterschied sich oft von Teilgebiet zu Teilgebiet. Welches Schicksal die nach Italien geflohenen Juden erwartete, hing vor allem davon ab, wem sie dort begegneten. Das Schicksal der ca. 1.400 in die Provinz Fiume (italienisch seit 1924) geflüchteten Juden war am härtesten, da der dortige Präfekt gleichermaßen aggressiv gegen Partisanen und geflüchtete Juden vorging. Ungefähr die Hälfte der Geflüchteten wurde wieder in das von den italienischen Truppen besetzte kroatische Gebiet abgeschoben. ${ }^{121}$ Bis September 1941 wurden dem Innenministerium $367 \mathrm{Ab}$ schiebungen gemeldet. ${ }^{122}$ Da zu dieser Zeit noch die Ustascha im italienisch besetzen Gebiet ungehindert ihre Macht ausüben konnte, ist anzunehmen, dass ein Teil der Abgeschobenen ihr in die Hände gefallen ist. Für diese Personen kam die Abschiebung einer Todesstrafe gleich. Nach der Übernahme der politischen und militärischen Gewalt in der II. Zone genossen Juden die Protektion

e Abbazia (1924-1945), Trieste 2004, S. 101 f.; Voigt: Zuflucht, S. 204-208. Eine persönliche Erinnerung: Niederschrift von Mladen Vranić, Toronto 2008, auf: http://www.croatianhistory.net/etf/vranic_v.html (18.3.2019).

118 NARA, T-821, R. 294, Nr. 513, Internamento nuovi ebrei, 27.4.1943.

119 Nach Milošević waren es 4.500 Juden, wovon sich 2.000 in der I. Zone und genauso viele in der II. Zone niederließen, und der Rest nach Montenegro und Kosovo ging. Milošević, Slobodan D.: Izbeglice i preseljenici na teritoriji okupirane Jugoslavije 1941-1945. Godine, Belgrad 1981, S. 226. Laut Klaus Voigt wurden alleine in Dalmatien mindestens 3.800 jüdische Flüchtlinge aufgenommen. Voigt: Zuflucht, S. 215.

120 Rodogno: Il nuovo ordine mediterraneo, S. 438.

121 Zur Abschiebungspraxis in Fiume siehe Rodgno: Il nuovo ordine mediterraneo, S. 440444; Tragisch ist die Geschichte des Rabbi Deutsch und der jüdischen Emigranten in Sušak, deren Liste der Rabbi dem Quästor übergab, weil dieser ihm versicherte, er wolle sie auf unterschiedliche Provinzen verteilen. Doch stattdessen lieferte er sie an die Ustascha aus, und der Rabbi selbst kam in das Lager Ferramonti, wo er schließlich starb. The Crimes Against Jews, S. 121 f. Voigt, Klaus: Zuflucht auf Widerruf. Exil in Italien 1933-1945, Bd. 2, Stuttgart 1993, S. 207-210.

122 Klaus Voigt hält die tatsächliche Zahl der Abschiebungen für höher. Voigt: Zuflucht, S. 208. Ende August 1941 kam vom Comando Supremo die Anweisung, die geflüchteten Juden auszuweisen. AJ, Fond 110, k. 739, Nr. 649, Ingresso clandestino di ebrei nel regno dalla frontiera italo-croata, 31.8.1941. 
der 2. Armee. Dies bedeutete, dass sie dort in der Regel sicher unterkommen konnten.

Die ca. 1.400 Juden, die bis Juli 1943 nach Slowenien flüchteten, wurden hingegen in der Regel nicht abgeschoben. Stattdessen überführten italienische Behörden sie zunächst in das Lager Ferramonti di Tarsia und später in die freie Konfinierung. ${ }^{123}$ Ähnlich erging es auch den jüdischen Flüchtlingen aus Belgrad in der Provinz Cattaro: Sie wurden zunächst geduldet, nach dem Ausbruch des Aufstandes in Montenegro nach Albanien abtransportiert und schließlich im September 1941 nach Italien überführt und ebenfalls im Lager Ferramonti interniert. ${ }^{124}$ Wie viele Personen letztlich in der „freien Konfinierung“ endeten, ist unklar. Nikola Moskatello, der Berater jugoslawischer Geschäfte im Vatikan, schrieb in einem Brief, dass „nur der liebe Gott und vielleicht auch die italienische Regierung alle Konfinierungsorte“ kenne. ${ }^{125}$

Die meisten Flüchtlinge - Juden wie Serben - flohen mit den einsetzenden Verfolgungen in Kroatien in Richtung Dalmatien. Dort lebten vorher nur $425 \mathrm{Ju}$ den - alle in Split, wo es auch eine jüdische Gemeinde gab. ${ }^{126}$ Diese war von Anfang an nicht in der Lage, alleine für die Flüchtlinge $\mathrm{zu}$ sorgen, so dass die italienischen Behörden mit Lebensmitteln und Geld helfen mussten. Unter ihrer Duldung wurden die Flüchtlinge mit Ausweisen ausgestattet, mit welchen sie auf italienischem Gebiet sicher waren. ${ }^{127}$ Doch waren beim örtlichen Zweig der faschistischen Partei antisemitische Kräfte vertreten, die mit den steigenden kommunistischen Anschlägen in den Juden eine Gefahr sahen und sie ,antiitalienischer Einstellung“ bezichtigten. ${ }^{128}$ So fand in Split auch die bis September 1943 größte Ausschreitung gegen Juden in ganz Italien statt. Eine Gruppe des faschistischen M Bataillons zerstörte am 12. Juni 1942 die Synagoge sowie eine jüdische Buchhandlung, verletzte ca. 50 Personen und verbrannte Dokumente, Bücher und die Einrichtung der Buchhandlung. Die italienischen Zivilbehörden

123 Voigt weist sechs Fälle von Abschiebungen nach. Voigt: Zuflucht, S. 212. Dreißig Weisenkinder konnten mit Hilfe der Delasem (Delegazione per l'Assistenza degli Emigranti Ebrei Eine von italienischen Juden 1939 gegründete Organisation, die jüdischen Flüchtlingen half) nach Norditalien gebracht werden. Von dort flüchteten sie nach der italienischen Kapitulation in die Schweiz und gingen schließlich nach Israel.

124 Ristović, Milan: U potrazi za utočištem. Jugoslovenski Jevreji u bekstvu od Holokausta 1941-1945, Belgrad 1998, S. 86-89. Auch 200-300 Juden aus Split sollten vorübergehend nach Albanien gebracht werden. Telegramm des Gouverneurs von Dalmatien an den Präfekt von Spalato, 8.8.1941, abgedr. i. NOB u Dalmaciji, Bd. 1, S. 547; Kečkemet, Duško: Židovi u povijesti Splita, Split 1971, S. 177.

125 Zit. nach Ristović: U potrazi za utočištem, S. 93.

126 Voigt: Zuflucht, S. 214.

127 Ristović: U potrazi za utočištem, S. 111-113.

128 Voigt: Zuflucht, S. 214. 
unternahmen nichts, um die Ausschreitungen zu beenden. Erst am nächsten Tag, als die Plünderung von jüdischen Geschäften weiter ging, setzte die Armee den Exzessen ein Ende. ${ }^{129}$

Die Regierung von Dalmatien stand dem Zufluss der Flüchtlinge aus logistischen, politischen und aus Gründen der inneren Sicherheit ablehnend gegenüber. ${ }^{130}$ Bastianini ordnete am 17. Juni 1941 an, die Flüchtlinge an der Einreise nach Dalmatien zu hindern und nur diejenigen zuzulassen, die genügend Geld hatten, um ihren Lebensunterhalt $z u$ bestreiten. Diese sollten sich an militärisch unbedeutenden Orten niederlassen. ${ }^{131}$ Bevorzugt wurde ihre Überführung nach Italien: Bis Dezember 1941 wurden 1.045 jüdische Flüchtlinge in italienischen Lagern auf der Halbinsel interniert. Danach ordnete das Innenministerium an, die Überführung weiterer Flüchtlinge einzustellen, nach Dalmatien strömten aber weitere 1.500 Personen. ${ }^{132}$ Etwa 700 Flüchtlinge wurden auf der Insel Korčula in „freie Konfinierung“ verbracht. Dort lebten sie unter relativ erträglichen Umständen bis zur italienischen Kapitulation. Allerdings wurden auch drei Juden (von insgesamt dreizehn Personen) im Rahmen von „Sühnemaßnahmen“ für „in den Wald“ geflüchtete Männer auf Korčula erschossen. ${ }^{133}$

Das Problem der Flüchtlinge blieb auch 1942 bestehen, obwohl Bastianini weiterhin versuchte, den Zustrom einzudämmen. Nachdem die Weiterleitung nach Italien ab Januar 1942 nicht mehr möglich war, wurden bis Ende August 1942 insgesamt 326 Personen vorwiegend nach Dubrovnik ausgewiesen. ${ }^{134} \mathrm{Im}$ Sommer 1942, auf dem Höhepunkt des deutsch-italienischen Tauziehens um die kroatischen Juden, die in das italienische Gebiet geflüchtet waren, ermächtigte Mussolini den Gouverneur, alle 1.500 Flüchtlinge aus Split auszuweisen. Doch Bastianini sprach sich gegen ihre Rückführung nach Kroatien aus, solange die

129 Kečkemet: Židovi, S. 178-180. Nach Kečkemet war es die einzige Aktion gegen die Juden in Split. Die Reaktionen der Bevölkerung waren so negativ, dass das Bataillon M anschließend die Stadt verlassen musste. Talpo: Dalmazia, Bd. 2, Einleitung, S. 253-256.

130 Carpi, Daniel: The Rescue of Jews in the Italian Zone of Occupied Croatia, in: Gutman, Yisrael/Zuroff, Efraim (Hg.): Rescue Attempts during the Holocaust. Proceedings of the Second Yad Vashem International Historical Conference, Jerusalem, April 8-11, Jerusalem 1974, S. 465-525, hier S. 470.

131 Gouverneur von Dalmatien an die Präfekten von Zara, Spalato und Cattaro, 17.6.1941, in: VEJ 14, Dok. 94, S. 349.

132 Vogt: Zuflucht, S. 216.

133 Kečkemet: Židovski sabirni logori, S. 121-124; Mošić, Aleksandar: Jevreji na Korčuli, in: Mi smo preživeli...Jevreji o holokaustu, hgg. v. Jevrejski istorijski muzej, Belgrad 2001, S. 179-191, hier S. 183-186. Unter den Konfinierten befand sich auch der österreichische Schriftsteller Theodor Tschokor, der seinen dortigen Aufenthalt im Roman Die Insel verarbeitet hat.

134 AUSSME, N 1-11, DS, b. 543, All. 489, al DS di novembre 1941, Allontanamento ebrei ed elementi indesiderabili zona demilitarizzata, 21.11.1941; Voigt: Zuflucht, S. 216. 
kroatische Regierung nicht glaubhaft versichern konnte, mit ihnen human zu verfahren und ihren anständige Lebensumstände zu bieten. ${ }^{135}$ Diese veränderte Haltung Bastianinis ist wohl dadurch zu erklären, dass die II. Armee im Sommer 1942 die zivilen Befugnisse in der II. Zone wieder an die Kroaten abgetreten hatte. Daher hatte er berechtigten Grund zur Sorge, dass die Juden das gleiche Schicksal wie bereits 1941 erwarten könnte. Als dann im Herbst 1942 die jüdischen Flüchtlinge in der II. Zone von Italienern interniert wurden, schob Bastianini auch ca. 1.100 Personen aus Split unter den Bedingungen der „freien Internierung“ in diese Lager ab. Als Italien kapitulierte befanden sich noch ca. 800 Juden in der Provinz Spalato und ca. 500 auf Korčula in „freier Konfinierung.. 136

Wiederum anders gestaltete sich die Situation in der II. Zone. Mit der Ausweitung der italienischen Befugnisse auf die II. und III. Zone wurde in Ambrosios Bekanntmachung vom 7. September 1941 explizit allen Bevölkerungsgruppen die gleiche Behandlung zugesichert. Die kroatischen Gesetze wurden zwar nicht außer Kraft gesetzt, doch mussten kroatische Behörden für alle Entscheidungen die Zustimmung der 2. Armee einholen. Darauf baute offiziell auch die Protektion der Juden auf. ${ }^{137}$ Einmal im italienischen Gebiet angekommen konnten die Juden somit ein relativ sicheres Leben führen.

In Dubrovnik wuchs die Zahl der Juden, nachdem die italienische Armee die Befehlsgewalt in der II. Zone übernommen hatte, auf ca. 1.200 an. ${ }^{138}$ Die wichtigste Rolle spielte hier der Befehlshaber des VI. Armeekorps, General Giuseppe Amico, der sich allen kroatischen Anfragen, die Juden auszuliefern, widersetzte. Nach der Rückkehr seiner Truppen nach Dubrovnik im September 1941 erteilte er den Kroaten der Befehl, alle Juden und Serben, die wegen ihrer Rasse, ihres Ursprungs oder ihrer Religion im Gefängnis saßen, zu befreien so-

135 Telegramm des Außenministeriums, GAB-AP an die it. Gesandtschaft in Zagreb, 3.6.1942, abgedruckt in Carpi: Rescue, S. $508 \mathrm{f}$.

136 ASMAE, GAB-AP 1923-1943, b. 1507, Ebrei rifugiati nella Dalmazia italiana, 29.7.1942; NARA, T-821, R. 405, Nr. 361, Internati ebrei nell'isola di Curzola, 9.4.1943; Voigt: Zuflucht, S. 217 f. 137 Auf den Bando als den Ursprung der Judenprotektion hat bereits Anna Millo verwiesen. Millo, Anna: L'Italia e la protezione degli Ebrei, in: Caccamo, Francesco/Monzali, Luciano (Hg.): L'occupazione italiana della Iugoslavia (1941-1943), Firenze 2008, S. 355-378, hier S. 371.

138 Diese Zahl stützt sich auf die Angaben von Emilio Tolentino, dem Vorsitzenden der jüdischen Gemeinde von Dubrovnik, der jedoch zwei unterschiedliche Zahlen angab: 1.200 und 1.600. Sie werden bei Shelah und Ristović zitiert. Voigt hingegen nennt, gestützt auf die Armeekorrespondenz, nur 200-250 Flüchtlinge. Shelah, Menachem: Kroatische Juden zwischen Deutschland und Italien. Die Rolle der italienischen Armee am Beispiel des Generals Giuseppe Amico 1941-1943, in: Vierteljahrshefte für Zeitgeschichte 41 (1993) 2, S. 175-195, hier S. 185; Ristović: U potrazi za utočištem, S. 115; Voigt: Zuflucht, S. 225. 
wie die Deportationen in die Konzentrationslager, die im Juli aus Zagreb befohlen worden waren, einzustellen. ${ }^{139}$ Amico erklärte bereits im Oktober 1941 zum Entsetzen seines deutschen Zuhörers -, dass die Italiener auch dazu da seien, „um die armen Verfolgten vor Brutalität und Terror zu schützen.“ Deutsche Berichte vom Herbst 1941 meldeten, dass die Juden in Dubrovnik volle Freiheit genossen, das Bad besuchten und mit italienischen Offizieren verkehrten. Im Mostar war die Situation nach deutscher Einschätzung noch „schlimmer“. Die Italiener enthoben alle von der kroatischen Behörde aufgestellten Kommissare für jüdische Geschäfte ihres Amtes. ${ }^{140}$ Weiterhin lebten italienische Offiziere und Juden ,in einem sehr herzlichen Einverständnis. Es wäre wiederholt gesehen worden, dass ital[ienische] Offiziere und Juden sich bei der Begrüßung geküsst“ hätten. ${ }^{141}$ Wohl als Reaktion auf solche Berichte verbot das VI. Armeekorps seinen Soldaten jeden Umgang mit Juden. ${ }^{142}$ Die nördliche Adriaküste (insbesondere die Ortschaften Crikvenica, Novi Vinodol, Selce und Kraljevica) bildete neben Dubrovnik und Mostar ein weiteres Zentrum, an dem sich jüdische Flüchtlinge sammelten. Auch dort müssen die ca. 1.200 jüdischen Flüchtlinge und italienische Soldaten enge Beziehungen gepflegt haben, über die sich der Befehlshaber des V. Armeekorps, Renato Coturri, beschwerte. ${ }^{143}$

Zum besseren Verständnis des italienischen Vorgehens ist die Vorstellung vom italienischen Imperium entscheidend. Um dieses aufzubauen war es nötig, den italienisch-kroatischen Kampf um die Vormachtstellung in den besetzten Gebieten zu gewinnen. Mögen in der Langzeitperspektive die Deutschen der gefährlichere Gegner gewesen sein, vor Ort und im Moment waren das die Kroaten. So nutzten die Italiener die kroatische Verfolgungspolitik, um langfristige politische Vorteile für sich herauszuholen. Es passte an dieser Stelle, dass das Imperium auch eine inklusive Seite haben sollte, die nun gegen die Kroaten ins Feld geführt werden konnte. So hatte das Versprechen der Gleichbehandlung aller Bevölkerungsschichten einen tieferen Sinn im Zusammenhang mit dem Aufbau des Imperiums: einerseits nutzte es bei der Partisanenbekämpfung, ${ }^{144}$ andererseits hatte es auch eine eindeutige Spitze gegen den NDH. All jene Be-

139 Shelah: Kroatische Juden, S. 181.

140 Ähnlich verfuhren die italienischen Behörden auch bei Kommissaren für serbische Geschäfte. Vgl. Kap. 5.1.

141 BArch, RH 31/III/5, Die Frage der Četnici, 7.10.1942; BArch, RH 31/III/8, Bl. 10, Mitteilung des dt. Oberleutnants Weis, 22.12.1941.

142 AUSSME, N 1-11, DS, b. 584, rac. 226, Nr. 3, Comando VI CdA, Norme per la 2. e 3. Zona. 143 AUSSME, N 1-11, DS, b. 1378, All. 325 al aprile/maggio 1942, Contegno con i appartenenti alla razza ebraica, 15.5.1942; Zu den Zahlen vgl. Tabelle 58 in: Rodogno: Il nuovo ordine mediterraneo, S. 529.

144 Siehe nächstes Kapitel. 
völkerungsgruppen, die sich unter den Italienern sicher fühlten, würden für eine Zugehörigkeit zu Italien und nicht zum NDH optieren. Auf diese Weise versuchte die italienische 2. Armee diese Gebiete für die Zukunft zu sichern. Damit dies funktionierte, musste das von der Armee propagierte Bild des starken aber gerechten Italiens erhalten bleiben. Die italienischen zivilen und militärischen Behörden betonten daher auch im Zusammenhang mit den Juden, dass das Recht regierte, und alle unter dem Schutz dieses Rechts standen. In Mostar lehnte es der Stabschef der Division „Murge“ ab, die Juden ihre Wohnungen räumen zu lassen, um diese der Organisation Todt zur Verfügung zu stellen. Er begründete diese Entscheidung damit,

...dass die italienische Armee allen Bevölkerungsteilen Mostars die gleiche Behandlung zugesichert habe, und alle Teile der Bevölkerung unter dem Schutz der italienischen Armee stünden. Es sei daher mit der Ehre des italienischen Heeres nicht vereinbar, gegen die Juden Sondermaßnahmen zu ergreifen... ${ }^{145}$

Bis zum Sommer 1942 mussten die Italiener allerdings nur kroatische Bitten um die Auslieferung der Juden abwehren. Dann sollte aber das italienische Gebiet in die erste von den Deutschen initiierte und geplante Verhaftungs- und Abtransportwelle einbezogen werden. Am 17. August wurde die italienische Regierung gebeten, sich dem deutsch-kroatischen Vorhaben anzuschließen. Bei der Überbringung dieser Bitte machte der deutsche Botschafter in Rom seinem italienischen Kollegen deutlich, dass auf die Juden „Auflösung und ihre komplette Vernichtung“ warteten. Dies machten die Mitarbeiter des Außenministeriums in ihrer Notiz an den Duce deutlich, der trotzdem sein „nulla osta“, also sein Einverständnis, ${ }^{146}$ gab. ${ }^{147}$ Als die Kroaten im September auf dieser Grundlage bei General Roatta um die Auslieferung der Juden ersuchten, weigerte dieser sich, die Juden zu übergeben. Pavelić beschwerte sich anschließend bei seinem Tref-

145 BArch, RH 31/III/8, Nr. 13, Schreiben des Ministerrates Schnell im Reichsministerium für Bewaffnung und Munition an das Auswärtige Amt, 18.7.1942.

146 Es gibt unterschiedliche Auslegungen des „nulla osta“. Die Mitarbeiter im Außenministerium sowie die Deutschen werteten das „nulla osta“ als Mussolinis Einverständnis. So wird es auch von den meisten Historikern gesehen. Davide Rodogno argumentiert hingegen, dass dadurch die Entscheidung der zuständigen Behörde überlassen wurde. Dies erscheint aber aus dem ganzen Kontext wenig einsichtig. Rodogno: Il nuovo ordine mediterraneo, S. 452.

147 Es existieren zwei Fassungen von der Notiz für den Duce. In der zweiten, ihm vorgelegten, wurden weite Passagen, die eine Argumentation gegen die Auslieferung beinhalteten, auf handschriftliche Anweisung von Ciano, die sich auf der ersten Fassung findet, herausgestrichen. ASMAE, GAB-AP 1923-1943, b. 1507, Appunto, 18.8.1942; Il Ministro degli esteri, Ciano, al Capo del governo, Mussolini, 21.8.1942, abgedr. i. DDI, IX/9, Nr. 52, S. 61. Vgl. Shelah, Menachem: Un debito di gratitudine. Storia dei rapporti tra l'Esercito Italiano e gli Ebrei di Dalmazia (1941-1943), Rom 1991, S. 77-79. 
fen mit Hitler darüber, der das Problem bald mit Mussolini erörtern wollte. ${ }^{148}$ Gleichzeitig setzte sich der Vatikan bei der italienischen Regierung dafür ein, dass die Juden in Kroatien nicht ausgeliefert würden. ${ }^{149}$

Die Italiener beugten sich dem wachsenden deutschen Druck, indem sie beschlossen, alle Juden in der II. Zone zu erfassen und in Konzentrationslagern zu internieren. Gleichzeitig sollte ihre Nationalität und „Zugehörigkeit“ (pertinenza) festgestellt werden. General Roatta argumentierte, dass von den höchstens 3.000 Juden im italienischen Gebiet die Meisten zur annektierten Zone gehören dürften, weil es nur wenige geschafft hätten, sich vor den Verfolgungen im $\mathrm{NDH}$ zu retten. Diese würden dann - das implizierte die Argumentation - zu Italien gehören und nicht ausgehändigt werden. Gleichzeitig betonte Roatta in seinem Schreiben an das Comando Supremo, dass die Juden, die sich darauf verließen, nicht behelligt oder aus der II. Zone entfernt $\mathrm{zu}$ werden, solange sie moralisch und politisch keinen Grund zur Klage gaben, sich korrekt verhielten. Ihre Ausweisung würde dem italienischen Ansehen schaden, da Italien sie wenn auch stillschweigend - unter seinen Schutz gestellt hatte. ${ }^{150}$ Dieser Bericht ist eine Zusammenfassung der Beschwerden, welche das Kommando der 2. Armee aus diversen Einheiten erreichten, nachdem die beschlossene Internierung der Juden bekanntgegeben worden war. ${ }^{151}$ Alle Beschwerden erinnerten gebetsmühlenartig an den Bando 7 settembre, der allen Bevölkerungsgruppen und somit auch Juden Leben und Eigentum garantierte. Darauf bezogen sich auch jüdische Flüchtlinge in ihrer Korrespondenz mit der 2. Armee. ${ }^{152}$

Als Anlass der Internierungen nannte das Kommando der 2. Armee in einem Schreiben an die Armeekorps „offensichtliche Gründe der Humanität“. 153 Mit dem Fernschreiben vom 8. November 1942 wurde zudem festgelegt, dass alle von der Internierung ausgenommen waren, die sich auf dem Gebiet der II.

148 AUSSME, GAB-AP 1923-1943, b. 1507, Richieste croate relative ad ebrei residenti nella zona di occupazione italiana, 12.9.1942; Aufzeichnung über die Unterredung zwischen dem Führer und dem Poglavnik, 25.9.1942, abgedr. i. ADAP, E, Bd. 3, Nr. 310, S. 530-538.

149 L'ambasciatore presso la Santa Sede, Guariglia, al Ministro degli esteri, Ciano, 5.11.1942, abgedr. i. DDI, IX/9, Nr. 278, S. $285 \mathrm{f}$.

150 ASMAE, GAB-AP 1923-1943, b. 1507, Ebrei in Croazia, 10.10.1942. Dieses Verfahren versprach, sich einige Monate hinzuziehen. Steinberg, Jonathan: Deutsche, Italiener und Juden. Der italienische Widerstand gegen den Holocaust, Göttingen 1992, S. $102 \mathrm{f}$.

151 NARA, R. 405, Nr. 833-835, Internamento degli ebrei residenti nella 2/a zona, 8.11.1942; NARA, R. 405, Nr. 695-697, Situazione ebrei, 27.8.1942; NARA, R. 405, R 296, Nr. 903 f., Ebrei del littorale adriatico, 14.11.1942; Entwurf ohne Überschrift und Datum, (dem Inhalt nach vom Herbst 1942), abgedr. i. Carpi: Rescue, S. 514 f.

152 Schreiben des Präsidenten der Jüdischen Gemeinde Mostar an das Oberkommando der 2. Armee, 4.12.1941, in: VEJ 14, Dok. 134, S. 406.

153 NARA, T-821, R. 405, Nr. 778. 
Zone befanden, aber aufgrund von kroatischen Gesetzen nicht als Juden galten sowie diejenigen, die von kroatischen Behörden „positiv diskriminiert“ wurden. ${ }^{154}$ Dabei handelte es sich um Juden, die von Pavelić „Arier-Rechte“ zugesprochen bekamen oder die mit „Ariern“ verheiratet waren. ${ }^{155}$ Damit wurden nur diejenigen Juden der II. Zone interniert, denen tatsächlich die Gefahr drohte, an die Deutschen ausgeliefert zu werden. Nach Cezar-Zadik Danon seien die Juden aus Mostar darüber informiert worden, dass die Italiener sie vor Ort nicht mehr beschützen könnten, und sie deshalb internieren würden. Diejenigen Juden, die trotzdem in Mostar blieben, würden keinen weiteren italienischen Schutz genießen. Fast alle beschlossen, in die Internierung zu gehen. ${ }^{156}$ Jüdische Ärzte, die sich mit Familien in Mostar befanden und noch „positiv diskriminiert" wurden, weil der kroatische Staat sie für die Bekämpfung der Epidemien in Bosnien brauchte, baten das VI. Armeekorps darum, in italienischen Lagern interniert zu werden oder an Orte transferiert zu werden, wo sich italienische Truppen befanden. Mit Bleistift schrieb ein italienischer Militär unter das Gesuch: „Ich halte den Vorschlag für gut, auch wenn er eventuell deutsche Proteste provozieren könnte.“ Der Bitte wurde entsprochen, die Ärzte sollten in Dubrovnik aufgenommen werden, mussten jedoch selbst anreisen und jede Werbung in dieser Sache vermeiden. ${ }^{157}$

In der Internierung ging die Feststellung der Zugehörigkeit weiter. Folgende Personen hatten Anspruch auf die italienische Staatsbürgerschaft: Diejenigen, die in einer Gemeinde der I. Zone geboren waren und jetzt dort lebten; diejenigen, die seit langer Zeit dort lebten; diejenigen, die dort entweder Immobilien oder Angehörige bis zum 3. Grad hatten und schließlich diejenigen, die sich besondere Verdienste um die italienischen Besatzungsbehörden erworben hatten. ${ }^{158}$ Trotz dieser weitumfassenden Bestimmungen wurde bereits zum 16. Dezember 1942 festgestellt, dass die überwiegende Mehrheit der internierten Juden - 2.353 von 2.662 - die kroatische Staatsangehörigkeit hatte. Sie wurden

154 NARA, T-821, R. 405, Nr. 473, Telescritto $n^{\circ}$ 12287/AC dell'8 novembre 1942. Eine ähnliche Praxis der „positiven Diskriminierung“ bestand auch in Italien. Vgl. Moos: Ausgrenzung, S. $56 \mathrm{f}$.

155 Vgl. NARA, T-821, R. 405, Nr. 199-202, Internamento ebrei, 28.3.1943.

156 Danon, Cezar-Zadik: Preživjeli smo II svjetski rat (Manuskript), S. 14.

157 NARA, T-821, R. 405, Nr. 302, 306, Fernschreiben, 2.6. und 3.6.1943.

158 Il Capo dell'ufficio del gabinetto, Baldoni, al Ministro degli esteri, Ciano, 6.11.1942, abgedr. i. DDI, IX/9, Nr. 278, S. 287 f. Ein Telegramm gleichen Inhalts vom Außenministerium, GABAP an Castellani vom 16.10.1942 ist abgedruckt bei Carpi: Rescue, S. $517 \mathrm{f}$. 
trotzdem nicht ausgeliefert. ${ }^{159}$ Kasche berichtete gleichzeitig nach Deutschland, dass ca. 700 Juden nach Italien ausreisen konnten. ${ }^{160}$

Da in Kroatien und Dalmatien auch Lager für Slawen existierten, die im Zuge der Partisanenbekämpfung interniert wurden, muss man sehr deutlich zwischen den beiden Arten von Lagern unterscheiden. Es machte - in Anbetracht der Umstände - einen großen Unterschied, ob man als Slawe oder als Jude interniert wurde. Sowohl aus italienischen und kroatischen Quellen, als auch aus den Erinnerungen der überlebenden Internierten geht hervor, dass sich die Lebensumstände der beiden Gruppen deutlich unterschieden. Während Slawen im Rahmen der Aufständischenbekämpfung interniert wurden, spielte sich die Internierung der Juden außerhalb dieser Logik und der in diesem Zusammenhang errichteten Lager ab. Dies zeigte sich deutlich an der Art ihrer Unterbringung sowie an ihren Lebensumständen im Lager. ${ }^{161}$

Ab November 1942 wurden folgende Lager für Juden errichtet: Porto Re (Kraljevica), Isola di Mezzo (Lopud), Gravosa (Gruž) und Kupari in Dubrovnik (Ragusa), sowie einige kleine Lager auf den Inseln Brač und Hvar. ${ }^{162}$ Abgesehen vom Lager Porto Re handelte es sich dabei eher um Konfinierung als um Internierung: Sie waren überwiegend in umfunktionierten Hotels untergebracht, die

159 ASMAE, GAB-AP 1923-1943, b. 1507, Situazione campi di concentramento degli ebrei internati.

160 Sundhaussen: Jugoslawien, S. 325.

161 Viele Schilderungen der Lebensumstände beruhen auf Zeitzeugenaussagen der Überlebenden. Diese Quellen bringen gewisse Probleme mit sich. Auf ein solches Problem, nämlich dass in solchen „gefilterten Erinnerungen“ die Schilderungen der italienischen Lager im Gegensatz zu Ustascha- und Nazilagern als Oasen wirken und die Italiener als Retter, hat zuletzt Ruth Nattermann hingewiesen. Die Probleme müssen, wie bei anderen Quellen auch, erkannt und berücksichtigt werden, auf diese Quellen darf aber aus einem missinterpretierten Wunsch nach „Objektivität“ nicht verzichtet werden. Dies umso mehr, als wir auf die Aussagen der Überlebenden angewiesen sind, um die Lebensumstände in den Lagern schildern zu können. Offizielle Dokumente geben hier nur die Verhältnisse auf dem Papier wieder, wobei die Realität meist eine ganz andere war. Vgl. Nattermann, Ruth: Italian Commemoration of the Shoah: A Survivor-Oriented Narrative and Its Impact on Politics and Practices of Remembrance, in: Pakier, Małgorzata/Stråth, Bo (Hg.): A European memory? Contested histories and politics of remembrance, New York [u.a.] 2010, S. 204-218, hier S. 208; Vgl. auch Browning, Christopher: Remembering Survival. Inside a Nazi Slave-Labor Camp, New York [u. a.] 2010, S. 12.

162 Es handelte sich dabei um folgende Lager: San Pietro (Supetar), Postire (Postira), Neresi (Nerežišća), Milna, Bol und San Martino (Sumartin) auf der Insel Brač (Brazza) sowie die Lager Lesina (Hvar), Gelsa (Jelsa) und Cittavecchia (Stari Grad) auf der Insel Hvar (Lesina). Diese Lager umfassten zwischen einem und 365 Internierte. Die Lager Cittavecchia, Gelsa, Bol, Neresi und San Pietro wurden bis zum 15. April 1943 aufgelöst. AUSSME, Rom, M 3, b. 64, Situazione degli internati civili alla data del 29 dicembre 1942; 1. febbraio 1943; 15 aprile 1943, 27 giugno 1943, abgedruckt in: Rodogno: Il nuovo ordine mediterraneo, S. 531-534. 
von den Carabinieri bewacht wurden, es gab jedoch keinen Zaun. ${ }^{163}$ Überall wurde den Internierten die Verwaltung der Lager übertragen und erlaubt, durch eigene Anstrengungen ihre Lebensumstände $\mathrm{zu}$ verbessern. Sie organisierten eine Schule für Kinder und Kurse für Erwachsene, andere Kultur- sowie Bildungsveranstaltungen und sorgten auch selbst für die innere Ordnung. ${ }^{164}$ In Kupari organisierten einige Vorkriegsmitglieder der KP auch ein Volksbefreiungskomitee, das sich mit den Bewohnern von Kupari verband und über sie Nachrichten empfing. Es war auch später auf Rab aktiv. Auch auf Hvar wurde ein solches Komitee gegründet. ${ }^{165}$ Das größte Problem stellte die unzureichende Lebensmittelversorgung dar. Im Lager Ragusa wurden deshalb aus eigenen Mitteln zusätzliche Nahrungsmittel gekauft. Weibliche Internierte bereiteten mit Hilfe dreier Soldatenköche das Essen zu. ${ }^{166}$

Die Situation der Juden im Lager Porto Re war deutlich schlechter. Die Internierten wurden in Baracken (Frauen und Kinder) und Ställen untergebracht und befanden sich hinter Stacheldraht. Im November 1942 besuchten kroatische Vertreter das Lager. Nach ihrem Bericht befanden sich im Lager 1.184 Personen. Tagsüber lebten die Familien zusammen, nur nachts schliefen die Männer getrennt. Die Internierten durften zwei Mal wöchentlich Besuch empfangen. Besonders positiv wurde im Bericht die Ernährungssituation beschrieben: Kaffee am Morgen, ${ }^{167}$ Nudeln zum Mittagessen und Reis zum Abendessen. Darüber hinaus bekamen sie 200 Gramm Brot täglich. Auch wenn sie dem Bericht nach somit mehr bekamen, als die kroatische Bevölkerung zur Verfügung hatte, so waren die Mengen immer noch nicht ausreichend. Die Internierten konnten diese Portionen jedoch durch Lebensmittelpäckchen sowie durch Zukauf sowohl in

163 Romano, Jaša: Jevreji u logoru na Rabu i njihovo uključivanje u Narodnooslobodilački rat, in: Zbornik 2. Studije i građa o učešću Jevreja u narodnooslobodilačkom ratu, hgg. v. Jevrejski istorijski muzej, Belgrad 1973, S. 1-68, hier S. 9 f. Vladimir Isaić, einer der Internierten, schreibt jedoch in seinen Memoiren, dass sie auf Lapud im Hotel Grand untergebracht waren, das nach den ersten Tagen mit Stacheldraht umzäunt wurde. Er schreibt aber auch, dass er als Kind mit Freunden oft durch den Zaun zum Baden „flüchtete“ und immer wieder von den Carabinieri zurückgebracht wurde, die schimpften, dass sie „wie Katzen entwischt wären“. Isaić, Vladimir: Put prognanih. Od Mostara do Raba 1942-1943, Split 2003, S. 33, 54.

164 USC Shoah Foundation Institute for Visual History and Education, University of Southern California, (USC Shoah Foundation Institute), Interview mit Atias, F. (w), Code Nr. 46538, Tape 3, Segment 67-72 (Hvar); Auslender, D. (m), Code Nr. 4839, Tape 2, Segment 44 (Lopud); Akerman, B. (w), Code 7053, Tape 3, Segment 85 (Kupari).

165 Deverić, Mišo/Fumić, Ivan: Hrvatska u logorima 1941-1945, Zagreb 2008, S. 93 f.; Romano: Jevreji na Rabu, S. 11, 14.

166 Romano: Jevreji na Rabu, S. 11.

167 Dieses „Frühstück“ konnte wohl kaum als eine Mahlzeit gelten und entsprach auch dem, was die slawischen Internierten bekamen, wobei es sich nicht um echten Kaffee handelte. 
der italienischen Kantine als auch außerhalb des Lagers aufbessern. Der Verfasser des Berichts folgerte daraus, die Juden wären für die Lebensmittelknappheit in der Gegend des Lagers schuldig. ${ }^{168}$ Es ist anzunehmen, dass die Situation der Juden schlechter war, als aus dem eindeutig parteiischen Bericht hervorgeht. Im Januar beschwerten sich die Internierten über ihre Situation - insbesondere über die sanitären Einrichtungen, die Ernährung, ihre Wertsachen außerhalb des Lagers sowie kulturelle und soziale Probleme - beim Kommando der 2. Armee, das von dem für das Lager zuständigen V. Armeekorps eine Erklärung verlangte. In dieser wurde eingeräumt, dass aufgrund von Mängeln, der schlechten Wetterverhältnisse und des steinigen Gebietes die Arbeiten an der Verbesserung des Lagers stockten. Da sich die Situation nicht verbesserte, führten die Internierten selbst eine Reihe von Veränderungen durch: Sie besserten die Baracken aus, funktionierten ein Gebäude zur Küche um und bauten zwei neue Baracken. Eine war für Neugeborene und ihre Mütter, in der anderen wurden eine Ambulanz, eine Apotheke, die Lagerleitung, das Lagergericht, ein Friseur und eine Näherei untergebracht. ${ }^{169}$ Arbeitende Internierte bekam dann auch die entsprechend besseren Essensportionen, nach italienischen Angaben 1.234 kcal täglich. ${ }^{170}$ Darüber hinaus wurde einzelnen Personen erlaubt, in Begleitung der $\mathrm{Ca}$ rabinieri $\mathrm{zu}$ ihren Wohnungen $\mathrm{zu}$ gehen, um Essen oder persönliche Gegenstände abzuholen. All diese Maßnahmen verbesserten die Lebensqualität in Porto Re deutlich, ehemalige Internierte beschrieben sie als erträglich. ${ }^{171}$

Eine Sorge jedoch blieb: Sie hatten Angst ausgeliefert $\mathrm{zu}$ werden, auch wenn die Italiener ihnen das Gegenteil versicherten. General Roatta hatte bei seinem Besuch im Lager den Internierten persönlich versichert, Italien würde nicht zulassen, dass jüdische Flüchtlinge in der II. Zone von der Ustascha in Vernichtungslager gebracht würden. ${ }^{172}$ Die kroatischen Behörden berichteten ebenfalls, die italienischen Militärs hätten bei jeder Gelegenheit gegenüber den

168 AJ, Fond 110, k. 739, Nr. 409, Bericht über die Situation im temporären it. militärischen Lager für Juden in Kraljevica, 24.11.1942.

169 Schreiben der Vertreter der Juden im Konzentrationslager Porto Re an den Befehlshaber der 2. It. Armee, 4.2.1943, abgedr. i. VEJ 14, Dok. 172, S. 473-477; Romano: Jevreji na Rabu, S. 12.

170 NARA, T-821, R. 405, Nr. 144, Computo valore nutritivo razione alimentare campo internati civili di Porto Re.

171 NARA, T-821, R. 405, Nr. 130, Esposto ebrei internati all'Ecc. il Comandante, 20.2.1943; USC Shoah Foundation Institute, Interview mit Ajzenstajn-Stojic, M. (w), Code Nr. 5149, Tape 1, Segment 51; Altaras, T (w), Code Nr. 11268, Tape 2.

172 USC Shoah Foundation Institute, Interview mit Altaras, T (w), Code Nr. 11268, Tape 2; Romano: Jevreji na Rabu, S. 8. MacGregor Knox sieht in Roattas Besuch einen taktischen Zug, bei dem er „Sicherheit für die Zukunft“ gesucht hätte. Knox, MacGregor: Das faschistische Italien und die „Endlösung“ 1942/43, in: Vierteljahrshefte für Zeitgeschichte (VfZ) 55 (2007) 1, S. 53- 
Juden betont, dass sie Gäste der italienischen Armee seien und sich über ihre Zukunft nicht sorgen müssten. ${ }^{173}$ Während die Militärs die Juden beruhigten, waren sich die italienischen Diplomaten dieser Gefahr durchaus bewusst. Im Frühjahr 1943 erwogen sie, die in unterschiedlichen Lagern der II. Zone verteilten Juden an einem Ort innerhalb der italienischen Grenzen zu versammeln. Neben möglichen Skandalen und militärischen Gefahren machte Castellani insbesondere darauf aufmerksam, dass das, was in diesen Lagern stattfand, nämlich eine halbwegs menschliche Behandlung der Juden, eine ständige Provokation für Italiens Verbündete darstellen und ihnen tausend Vorwände bieten könnte, um darauf zu drängen, die Juden nach Deutschland oder Kroatien zu transferieren. ${ }^{174}$ Tatsächlich hatte Ribbentrop im Februar 1943 bei Mussolini persönlich das Thema erneut zur Sprache gebracht. Mussolini hatte sich wieder mit der Auslieferung einverstanden erklärt, doch er wies Roattas Nachfolger, General Robotti an, sich jede mögliche Ausrede einfallen zu lassen, um keinen einzigen Juden auszuliefern. ${ }^{175}$

Im Juni 1943 konzentrierte die 2. Armee die Juden auf italienischem Gebiet, nämlich im Lager Arbe auf der gleichnamigen Insel (Rab). Nach italienischen Angaben sollten insgesamt 2.661 Personen nach Rab transferiert werden: 1.172 aus Porto Re, 874 aus den Lagern in Dubrovnik und 615 von Hvar und Brač. Nach Angaben von Jaša Romano befanden sich in Arbe ca. 3.600 Juden. ${ }^{176}$ Das Lager hatte alle Kennzeichen eines Konzentrationslagers: Stacheldraht, Wachtürme, Reflektoren, permanente Wachen am Lagereingang usw. Innerhalb des jüdischen Lagers wurden zwei Bereiche geschaffen, die mit Stacheldraht voneinander getrennt waren: In dem Teil mit gemauerten Unterkünften wurden die Internierten aus den Dubrovnik-Lagern untergebracht, im Teil mit Holzbaracken die Internierten aus Porto Re, und von den Inseln Brač und Hvar. ${ }^{177}$ Die Lebensbedingungen in Arbe waren deutlich schlechter als in den vorherigen Lagern. Die Bewachung war strenger und die Internierten deutlich mehr von der Außenwelt abgeschnitten. Die Lagerverwaltung, die Aufrechterhaltung der Ord-

92, hier S. 87. Wenn dies durchaus eines der Motive gewesen sein kann, so war dieser Auftritt aber nur konsistent mit Roattas Judenpolitik, die er konsequent die ganze Zeit über verfolgte. 173 AJ, Fond 110, k. 739, Nr. 409, Bericht über die Situation im temporären it. militärischen Lager für Juden in Kraljevica, 24.11.1942.

174 ASMAE, GAB-AP 1923-1943, b. 1507, Appunto per l’Eccellenza il Ministro Pietromarchi, 20.3.1943.

175 Rodogno, Davide: Italiani brava gente? Fascist Italy's Policy towards the Jews in the Balkans, April 1941-July 1943, in: European History Quarterly, 35 (2005) 2, S. 213-240, S. 230.

176 NARA, T-821, R. 405, Nr. 131, Sistemazione Ebrei, 18.2.1943; Romano: Jevreji na Rabu, S. 17-19.

177 Romano: Jevreji na Rabu, S. 16. 
nung sowie die Essenszubereitung wurden jedoch weiterhin den Internierten überlassen. Dafür wählten sie eine Leitung. Diese formierte unterschiedliche Gruppen, die sich um die Verbesserung der hygienischen Verhältnisse oder des Essens kümmerten. Doch die Essensrationen reichten trotzdem nicht aus. Durch Arbeit konnten die Internierten diese ein wenig aufbessern: Einige weibliche Internierte nähten Uniformen, andere arbeiteten in Krankenhäusern. Sie besaßen nach wie vor eine gewisse Autonomie, die sich in der Selbstverwaltung des Lagers äußerte: Sie organisierten Schulen, eine Krankenstation und kulturelle Betätigungsmöglichkeiten auf dem Lagergelände. ${ }^{178}$ Jaša Romano, der die erste Monografie über die Verfolgung der Juden Jugoslawiens schrieb, urteilte: „Dank der Maßnahmen, die Internierte selbst zur Verbesserung der Lebensqualität unternommen haben, sowie des toleranten Umgangs des italienischen Lagerkommandos, war das Leben auf Rab relativ erträglich.“179

In Anbetracht der Tatsache, dass auf der Insel Rab seit Sommer 1942 ein großes Lager für Slawen existierte (das ebenfalls Arbe hieß), in dem katastrophale und menschenunwürdige Umstände herrschten, muss betont werden, dass die Juden in einem durch die Straße, die vom Ort Rab nach Lopare führte, sowie Stacheldraht und Extrawachen getrennten Teillager untergebracht waren. Das italienische Kommando achtete besonders darauf, dass kein Kontakt zwischen den beiden Lagern erfolgte. ${ }^{180}$ Die Eigenständigkeit der beiden Teillager äußerte sich auch in sehr unterschiedlichen Regimen in den beiden Lagern. Die Juden sollten zwar wie Internierte behandelt werden, aber mit Rücksicht auf ihre heterogene Zusammensetzung (Geschlecht, Alter, Sozialstatus) eine besondere Behandlung genießen. Dazu sollte ihnen mit einer ,angebrachten Toleranz" begegnet und die Unterbringung mit Hilfe der Internierten systematisch verbessert werden. Des Weiteren sollten eine Grundschule und ein Gymnasium eröffnet, eine Bibliothek gebildet, kulturelle Veranstaltungen abgehalten, sowie das Baden im Meer erlaubt werden. Einzelnen Personen wurde sogar gestattet, ihre Familienangehörigen im Lager Arbe zu besuchen. ${ }^{181} \mathrm{Im}$ Lager für Slawen

178 Romano: Jevreji na Rabu, S. 17; Isaić: Put prognanih, S. 64 f.; USC Shoah Foundation Institute, Interview mit Altaras, T (w), Code Nr. 11268, Tape 2; Atias, F. (w), Code Nr. 46538, Tape 3, Segment 83, Code 19182, Altatrac Franzos, C. (w), Video 3, Segment 81, 83; Code 7053, Akerman, B. (w), Tape 3, Segment 88-92.

179 Romano: Jevreji na Rabu, S. 20.

180 Romano: Jevreji na Rabu, S. 16. Zum Lager für Slawen siehe: Ruzicic-Kessler: Italiener auf dem Balkan, S. 279-283 sowie Ferenc, Tone: Rab-Arbe-Arbissima. Konfinacije, racije in internacije v Ljubljanski pokrajini 1941-1943. Dokumenti, Ljubljana 2000.

181 Ferenc: Rab, Dok. 468, Sistemazione e trattamento ebrei ad Arbe, 14.7.1943, S. 414 f.; NARA, T-821, R. 405, Nr. 405, 407, Autorizzazione visita internato ebreo al campo di Arbe, 15.8.1943; NARA, T-821, R. 405, Nr. 452, Autorizzazione, 24.8.1943. 
befanden sich am Anfang auch viele Frauen, Kinder und Alte, eine solche Behandlung haben sie aber nie erfahren.

Nach dem italienischen Ausscheiden aus dem Krieg bleiben etwa 200-300 Juden auf der Insel, während die große Mehrheit mit den Partisanen ging, welche die Insel vor den Deutschen erreicht hatten. Als letztere die Insel besetzten wurden all diejenigen, die geblieben waren, nach Auschwitz deportiert. Im Oktober 1943 verbrachte die Gestapo als letzte ca. 200 Juden aus Split in das Lager Semlin, wo die Männer an der Ausgrabung und Verbrennung der Leichen aus den Massengräbern in Jajinci arbeiten mussten und danach selbst ermordet wurden. ${ }^{182}$ Von den 38.000-40.000 Juden aus dem NDH überlebten nur ca. 7.000-9.000 den Holocaust. ${ }^{183}$ Der italienische Beitrag zur Rettung dieser Juden war relativ groß: ein gutes Drittel von Ihnen befand sich bis zum September 1943 auf den von Italien annektierten und besetzten Gebieten und vielen weiteren gelang es, Italien oder darüber auch andere neutrale Länder zu erreichen.

Das Verhalten der italienischen militärischen und zivilen Behörden gegenüber den Juden, hat in der historischen Forschung viel Aufmerksamkeit erregt. Viele Historiker haben versucht, das italienische Verhalten zu erklären und dabei komplexe Antworten auf die Frage zu geben, warum die Italiener einen Teil der Juden in den von ihnen besetzten Gebieten Frankreichs, Griechenlands und Jugoslawiens beschützt bzw. gerettet haben. Vor allem jüdische Autoren erklären das italienische Verhalten durch die Moral und die Menschlichkeit der Italiener und gehen sogar so weit, dem italienischen Volk als Kollektiv eine gewisse Menschlichkeit zuzusprechen. ${ }^{184}$ Sowohl Menachem Shelah als auch Jonathan Steinberg vertreten die These von einem Widerstand bestimmter Mitarbeiter des

182 Zur Rettung durch die Partisanen siehe: Kerenji, Emil: „Your Salvation is the Struggle Against Fascism": Yugoslav Communists and the Rescue of Jews, 1941-1945, in: Contemporary European History 25 (2016) 1, S. 54-74, hier S. 63-68; Romano: Jevreji Jugoslavije, S. 151; Löwenthal, Zdenko (Hg.): Zločini fašističkih okupatora i njihovih pomagača protiv Jevreja u Jugoslaviji, Belgrad 1952, S. 44 f. Bei der Ausgrabung der Leichen handelte es sich vermutlich um ein Kommando der Aktion 1005, das die Spuren der deutschen Verbrechen in Ost- und Südosteuropa beseitigen sollte. Angrick, Andrej: „Aktion 1005“ - Spurenbeseitigung von NS-Massenverbrechen 1942-1945. Eine „geheime Reichssache“ im Spannungsfeld von Kriegswende und Propaganda, Göttingen 2018.

183 Cvetković, Dragan: Holokaust u Nezavisnoj Državi Hrvatskoj - numeričko određenje, in: Istorija 20. veka 29 (2011) 1, S. 163-182; Goldstein: Judengenozid, S. 329.

184 Steinberg: Deutsche, Italiener und Juden; Shelah: Rescue; Shelah: Un debito di gratitudine. $\mathrm{Zu}$ dieser Ansicht trug auch Hannah Arendt mit ihrer Beschreibung des italienischen Verhaltens in ihrem Buch über den Eichmann-Prozess bei. Arendt, Hannah: Eichmann in Jerusalem. Ein Bericht von der Banalität des Bösen, München [u. a.] 2006, S. 283. 
Außenministeriums sowie Angehöriger der 2. Armee gegen die Auslieferung der Juden. Nach ihnen gab es eine Verschwörung, um die Juden zu retten. ${ }^{185}$ Die neuere, vor allem italienische Forschung hat die These von der Verschwörung verworfen, und es hat sich die Meinung etabliert, dass es in erster Linie politische Motive waren, auch in Hinblick auf die Nachkriegszeit, die das italienische Verhalten erklären. Die wichtigsten dabei waren die Differenz zwischen Faschismus und Nationalsozialismus, die wachsende Opposition in der Armee und bei hohen Beamten gegen die pro-deutsche Politik von Mussolini, die deutsch-italienischen Spannungen und schließlich die Einsicht, dass bei einer Niederlage der Achse die Rettung der Juden ein nützlicher Trumpf bei den Verhandlungen mit den Alliierten sein würde. ${ }^{186}$ Vor allem Macgregor Knox betonte den Zusammenbruch Italiens und die damit einhergehenden Aussichten auf einen Separatfrieden sowie die Hoffnung, von den Alliierten anders beurteilt zu werden, als den entscheidenden Faktor, ,der den Willen der Armee und des Außenministeriums zur ,Verteidigung der Juden im Jahre 1943‘ festigte“. ${ }^{187}$ Jüngst versuchte Karlo Ruzicic-Kessler eine erste Zusammenführung der beiden Argumentationen, indem er die politischen Motive anerkannte, jedoch auch betonte, dass die Erfahrungen der italienischen Soldaten und Offiziere vor Ort entscheidend für ihr Eingreifen zugunsten der Juden waren, die 1941 noch nicht an eine Abrechnung nach dem Krieg gedacht hätten. ${ }^{188}$

Ruzicic-Kesslers Argumentation ist definitiv zuzustimmen, wenn auch eine politische Implikation bisher aber doch vernachlässigt worden ist - das Bestreben, ein Imperium aufzubauen. Italien war in Kroatien, um sein Imperium territorial aus- und inhaltlich aufzubauen. Für die rein territoriale Ausdehnung stellten die Juden - ähnlich wie Serben oder besser alle Bewohner der besetzten Gebiete, die sich der italienischen Führungsrolle unterstellten - eine „Manövriermasse“ dar. Dies bedeutete, dass sie, wenn man sie vor den Verfolgungen beschützte, für Italien optieren würden. Mit genügend Optanten hätte Italien in der Zukunft die mit dem NDH strittigen Gebiete für sich beanspruchen können. Diese politische Denkweise mag in der Wehrmacht nicht verbreitet gewesen sein, die italienischen Generäle dachten durchaus in diesen Kategorien. Als der deutsche Druck im Sommer 1942 einsetzte, verfasste das Kommando des VI. Armeekorps eine Denkschrift, in der es alle vom 7. September 1941 bis dato getroffenen Entscheidungen der 2. Armee zugunsten der jüdischen Flüchtlinge fest-

185 Steinberg: Deutsche, Italiener und Juden, S. 84.

186 Rodogno: Il nuovo ordine mediterraneo, S. 476-484; Rodogno: Italiani brava gente, S. 213-240, insbesondere S. 220; Knox: Die „Endlösung“; Sarfatti, Michele: Gli ebrei nell’Italia fascista. Vicende, identità, persecuzione, Turin 2000.

187 Knox: Die „Endlösung“, S. 91.

188 Ruzicic-Kessler: Italiener auf dem Balkan, S. 172-209. 
hielt und, wie viele andere, feststellte, dass Juden keine Probleme bereiteten. Darüber hinaus machte es darauf aufmerksam, dass Dubrovnik eine Bevölkerung von 9.500 Personen hätte, „Italiener bis heute 4.200; plus die Juden“. Bei einem möglichen Plebiszit hätten diese somit das Zünglein an der Waage zugunsten Italiens sein können. ${ }^{189}$

Solche Überlegungen waren in italienischen militärischen und diplomatischen Kreisen nur deshalb möglich, weil das „Judenproblem“ in Italien einen anderen Stellenwert als in Deutschland hatte. Der Antisemitismus war anderen, wichtigeren, Themen - in diesem Fall der Expansion - unterzuordnen. ${ }^{190}$ Die andere Seite dieser Medaille sind die weniger greifbaren Dinge, wie das von den Faschisten propagierte Image in den annektierten bzw. besetzten Gebieten. Dazu gehörte die Absicht, alle Bevölkerungsgruppen gleich zu behandeln, die mit der Übernahme der Befehlsgewalt in der II. Zone öffentlich gemacht wurde. Dies wirkte sich auch auf die Politik gegenüber den Juden aus. Dadurch sollten sich die Italiener nicht nur von den „barbarischen“ Kroaten und Deutschen abgrenzen, sondern auch ein positives Bild aufbauen, dass auf die Bevölkerung der annektierten bzw. besetzten Gebiete attraktiv wirken sollte. ${ }^{191}$ Davide Rodogno hat festgestellt, dass die Bezüge auf Humanität und Pietät dafür benutzt worden seien, eine italienische und faschistische Identität gegenüber den Völkern des Balkans und auch gegenüber den Deutschen zu schaffen. Der faschistische Eroberer sollte nicht gut oder sentimental, aber auch nicht primitiv oder barbarisch, sondern gerecht und human sein. Er betont auch den lokalen Kontext, in dem man italienisches Verhalten gegenüber den Juden in Kroatien und Griechenland sehen müsse. Für ihn tritt dieses Motiv aber mit dem deutschen Antrag um Auslieferung in den Hintergrund und die deutsch-italienischen Spannungen und Kämpfe um die Oberhand im italienischen spazio vitale in den Vordergrund. ${ }^{192}$ Doch war die faschistische imperiale Identität, wie im Kapitel

189 NARA, R. 405, Nr. 695-697, Situazione ebrei, 27.8.1942. Dubrovnik war dem NDH zugefallen, Italien hätte die Stadt wegen seiner Geschichte und der strategisch wichtigen Position jedoch gerne annektiert. Ähnlich verhielt es sich auch mit einigen der kroatischen Inseln.

190 Siehe auch Cattaruzza: L'Italia e il confine orientale, S. 215, FN 34, eliminatorischer Antisemitismus.

191 Die Kroaten entwickelten Gegenentwürfe, die sie der italienischen lateinisch-mediterranen oder der „römischen“ kulturellen Überlegenheit entgegen setzten. Bartulin: The NDH as a ,Central European Bullwark against Italian Imperialism', S. 69. Auch die Deutschen fühlten sich durch italienische Vorstellungen beleidigt. Siehe Meir, Michaelis: Mussolini and the Jews: German-Italian relations and the Jewish question in Italy 1922-1945, Oxford 1978, S. $325 \mathrm{f}$.

192 Rodogno: Il nuovo ordine mediterraneo, S. 447-449, 480; Rodogno: Italiani brava gente, S. 216, 219. Auch McGregor Knox spricht von den „damaligen Überzeugungen der handelnden Personen“ als einem möglichen Motiv für ihr Handeln, wobei er hier insbesondere auf die Vorstellung der „italiani brava gente“ abzielt. Knox: Die „Endlösung“, S. 69 f. 
zwei dargestellt, ein das ganze italienische Imperium umfassendes Konstrukt, das nicht ad hoc in Jugoslawien entstanden ist, dort (und anderswo) aber aufgrund der Situation durchaus Anwendung fand - und zwar in der ganzen Zeit der Besatzung. Daher ist es für das Verständnis der Handelnden vor Ort auch für die Zeit ab dem Sommer 1942 durchaus wichtig, nach den Prämissen zu schauen, die von Beginn der Besatzung an verfolgt wurden.

Das faschistische Italien rühmte sich damit, dass es den besetzten Völkern die „römische Gerechtigkeit“ brachte, vor der alle Bevölkerungsgruppen gleich sein sollten. Es bot allen den italienischen Schutz an, doch die Voraussetzung war, dass sie die Vorherrschaft der italienischen Zivilisation anerkannten und gegebenenfalls bereit waren, sich $\mathrm{zu}$ assimilieren. Während für die Kroaten durch die Schaffung des kroatischen Staates diese Option nicht besonders verlockend war, stellten die italienischen Schutzangebote für die im NDH verfolgten Serben und Juden (und später bis zu einem gewissen Grad auch für die Muslime) die Rettung bzw. eine echte Alternative dar. So spielte im Umgang mit den jüdischen Flüchtlingen die Tatsache, dass sie die italienische Herrschaft nicht in Frage stellten und sich kaum am Aufstand gegen die Italiener beteiligten, eine wichtige Rolle. ${ }^{193}$ Im Gegenteil vertrauten sie auf die italienische „Gerechtigkeit“ und legten ihr Leben in italienische Hand. Damit erfüllten sie - noch mehr als die Serben des NDH - nicht nur das italienische Bedürfnis, ihr „Prestige“ $\mathrm{zu}$ wahren, sondern bekräftigten auch das propagierte Image von dem „gerechten“ Italien. Da die Flüchtlinge in der großen Mehrheit nicht gegen die Interessen Italiens handelten, konnte das „italienische Imperium“ seine vielgerühmte „Generosität“ an ihnen demonstrieren. So nutzten diesmal die Generäle den Antisemitismus und die „Judenfrage“, um die eigene faschistische Identität gegenüber sowohl der Ustascha als auch den nationalsozialisten zu akzentuieren. 194

193 Wie ein Propagandabericht vom September 1942 meldete, lebten die Juden zurückgezogen, kümmerten sich um ihre Belange und gaben keinen Grund zur Klage. AUSSME, N 1-11, DS, b. 859, Relazione mensile sul servizio „Propaganda“, Df Murge, 18.9.1942, S. 9. Ähnlich auch NARA, T-821, R. 405, Situazione ebrei, 27.8.1942, teilw. abgedruckt bei Steinberg: Deutsche, Italiener und Juden, S. 85. Die Konsistenz dieser Politik zeigt auch das bereits zitierte Schreiben von General Roatta an das Comando Supremo vom Januar 1943, in dem er sogar die gleiche Sprache benutzte. Die Flüchtlinge würden geduldet und sogar beschützt, solange sie moralisch oder politisch keinen Grund zur Klage gaben. ASMAE, GAB-AP 1923-1943, b. 1507, Ebrei in Croazia, 10.10.1942.

$194 \mathrm{Zu}$ ähnlichen Abgrenzungen in der Vorkriegszweit zwischen Deutschland und Italien siehe Bernhard: „The Great Divide?“. 


\subsection{Divide et impera, Teil 1: Welche Rolle für die Zivilbevölkerung?}

Bereits 1941 lamentierte Glaise von Horstenau, die italienische Politik sei „ganzen Lösungen nicht zugeneigt, sondern [wolle] im Augenblick das Bestmögliche herausschlagen. “195 Während die Politiker in Rom sowie die italienischen Diplomaten in Zagreb 1941 auf ein Bündnis mit dem kroatischen Staat setzten, war die in Kroatien stationierte italienische Armee durch ihre ablehnende Haltung gegenüber den Kroaten und ihrem Staat gekennzeichnet. Dabei war das Verhalten der maßgeblichen Offiziere in Schlüsselstellungen, also der Divisions- und Korpskommandeure sowie der Führung der 2. Armee entscheidend. ${ }^{196}$ Sowohl Ambrosio als auch Roatta hielten es für falsch, diesen Italien gegenüber im Grunde feindlich eingestellten Staat überhaupt geschaffen zu haben. ${ }^{197}$ Durch ihre Ablehnung der Kroaten boten sich Serben zwangsläufig als Verbündete an. Die Verfolgung der Serben und Juden im Frühjahr/Sommer 1941 hatte die Soldaten schockiert und Abscheu gegen den kroatischen Verbündeten hervorgerufen. Doch dies alleine hätte nicht zu einer generellen Änderung der italienischen Politik geführt. Die italienischen Befehlshaber dachten sehr politisch und machten ihre Entscheidungen von italienischen strategischen Zielen in Kroatien abhängig. Ihre Politik konnten sie deshalb umsetzen, weil sie weitestgehend unabhängig von den politischen Vorgaben aus Rom handelten.

Bereits zu Beginn der Besatzung informierten sich die Italiener über die genaue Zusammensetzung des Landes. In einem Befehl vom April 1941 wurde bereits auf die unterschiedlichen ethnischen Abstammungen der Bevölkerung im Besatzungsgebiet sowie ihre Animositäten hingewiesen. Die Soldaten wurden angewiesen, sich umsichtig und besonnen zu verhalten, da diese Bevölkerungsgruppen versuchen würden, sich Italien anzunähern, um so Vorteile für sich herauszuholen. ${ }^{198}$

Die Serben boten sich nicht nur wegen ihrer zahlenmäßigen Stärke und der feindlichen Einstellung gegenüber dem kroatischen Staat als Verbündete an. Auch das von Anfang an klare Bekenntnis der serbischen Aufständischen, keine

195 BArch, RH 31/III/1, Bl. 129, Fernschreiben des Dt. Bev. Generals in Kroatien, 24.12.1941.

196 Ähnlich hält Ben Shepherd die Haltung der deutschen „key officers“ für entscheidend, sowohl bei der 104. I. D., die im Sommer 1941 in Serbien deutlich weniger brutal vorgegangen ist als andere Divisionen, als auch der 342. I. D., welche die Befehle sogar noch verschärfte. Shepherd: Terror in the Balkans, S. 118, 126-128.

197 BArch, RH 31/III/8, Bericht über den ersten Empfang des Leiters des Deutschen Verbindungsstabes bei S. E. Roatta, 26.1.1942.

198 ASMAE, AP, JU 1941, b. 106, Bosnia Erzegovina, 10.5.1941; AUSSME, N 1-11, DS, b. 726, All. 435, Contegno nei territori occupati e da occupare, 13.4.1941. 
italienischen Truppen anzugreifen, spielte hierbei eine wichtige Rolle. Daher setzten die Italiener von Anfang an auf eine sehr enge Zusammenarbeit mit den Tschetniks. Vom militärischen Standpunkt aus war dies sicherlich die richtige Entscheidung, denn die Tschetniks bzw. die serbischen MVAC ließen sich sehr gut im Kampf gegen die kommunistischen Partisanen benutzen. Mit ihrer Hilfe konnten weitere Teile des Gebietes kontrolliert und die eigenen Verluste reduziert werden. ${ }^{199}$ Diese Zusammenarbeit sollte sich für die serbische Bevölkerung als Segen erweisen. Eine zwangsläufige Folge dieser Entscheidung war, dass andere Bevölkerungsgruppen das Nachsehen hatten. So verhinderte die italienische Armee die Verbrechen der Tschetniks an Katholiken und Muslimen nicht, sie entschuldigte sie gar als „natürliche Folge“ der Gewalttaten gegen die Serben vom Sommer $1941 .^{200}$ Auch bemühten sich die Italiener nur halbherzig um die muslimische Bevölkerung. Hier zeigen sich auch deutlich die Grenzen der von Italien propagierten Gleichbehandlung. Da diese politischen und militärischen Zielen diente, musste sie gegebenenfalls anderen Strategien, weichen.

Die Behandlung der Juden (genauso wie der Serben) in Kroatien passte genau in das von den Italienern propagierte Bild über die Art ihres Imperiums und fügte sich nahtlos in die von Italien vom Beginn an verfolgte Politik in Dalmatien und Kroatien. Daher ist anzunehmen, dass das Bild von einem humanen italienischen Soldaten, der eine gerechte faschistische Ordnung brachte, ein Konzept war, das größeren Anteil an der Rettung der Juden hatte, als bisher angenommen. Auch die Verweise Roattas darauf, dass man die Juden nicht ausliefern könnte, weil das negative Konsequenzen bei den Serben bzw. Tschetniks hervorrufen würde, passen hierzu. Dabei war Roatta nicht wirklich darum besorgt, dass die Tschetniks deshalb ihre Zusammenarbeit aufkündigen würden sie hatten schließlich kaum andere Alternativen. Aber er fürchtete um das italienische Image, das diese Zusammenarbeit erst ermöglicht hatte, sowie um das italienische Prestige, wenn er eine andere Politik verfolgen würde. ${ }^{201}$

Die Humanität und Gerechtigkeit spielten somit eine wichtige Rolle bei der Rettung der Juden. Im militärischen und politischen Kontext der Besatzung waren dies Werte, denen eine politische Rolle zugedacht war, indem sie ein Bild kreierten, das vom Beginn der Besatzung unter der Armee kultiviert sowie der Bevölkerung vermittelt wurde. Dies geschah in Dalmatien von Anfang an und

199 Siehe auch Monzali: La difficile alleanza, S. 100.

200 BArch, RH 31/III/5, Die Frage der Četnici, 7.10.1942.

201 Auch Jonathan Steinberg sieht darin einen von Roatta vorgeschobenen Grund, doch meint er, dass es deutlich weniger brauchte als die Auslieferung der Juden, um die sowieso illoyalen Tschetniks in die Berge verschwinden zu lassen. Steinberg: Deutsche, Italiener und Juden, S. 90. Davide Rodogno sieht hingegen hierin einen echten Grund für Roatta, die Juden nicht auszuliefern. Rodogno: Italiani brava gente, S. 219. 
im besetzten Teil Kroatiens nach dem 7. September 1941. Die italienische Armee versprach, alle gleich $\mathrm{zu}$ behandeln, ungeachtet der Religion, der ethnischen Zugehörigkeit oder des sozialen Status. Am Anfang sollten diese Werte der Bevölkerung als genuin italienisch vermittelt und dadurch den Slawen Dalmatiens und Kroatiens die Vorzüge der Zugehörigkeit zu Italien gezeigt werden. Später wurden zusätzlich die Vorteile der dezidierten Distanzierung von der deutschen (Juden-)Politik erkannt. Dies führte dazu, dass Juden (und Serben) auf den Schutz der Italiener bauen konnten. Wenn man die gesamte italienische Politik von Anfang an verfolgt, dann wird man sich darauf einlassen müssen, dass diese einer „kohärenten Logik“ folgte. ${ }^{202}$ Das macht die Italiener sicherlich nicht zur „brava gente“, zu der sie nach dem Krieg stilisiert wurden. Doch entfernt ihr Verhalten in Kroatien die Italiener von dem „redemptive antisemitism“ der Deutschen ${ }^{203}$ und auch von anderen deutschen Verbündeten, die sich williger an der „Endlösung“ beteiligten.

Ähnlich wie die Italiener gingen auch die Deutschen nach dem Divide-et-impera-Prinzip vor, jedoch mit einem anderen Ausgang: Um den NDH nach ihren Vorstellungen auszubeuten setzten sie komplett auf die Ustascha. Folglich ließen sie dieser freie Hand, achteten zumindest am Anfang die kroatische Souveränität und mischten sich nicht in die innerkroatischen Auseinandersetzungen ein. Die Serben wurden auch hier zunächst als Feinde betrachtet. ${ }^{204}$ Daraus und aus der schwachen Militärpräsenz in Kroatien speiste sich auch das allgemeine Desinteresse an der Bevölkerung Kroatiens. Glaise von Horstenau warnte im Sommer 1941 vor Einmischungen in innerkroatische Angelegenheiten, weil die deutschen Truppen gar nicht die Möglichkeit hätten, ihre Ansichten durchzusetzen, bzw. eine bestimmte Gruppe zu beschützen. Dabei hätte die Wehrmacht durchaus die Möglichkeit gehabt, die Bevölkerung zu beschützen, wie sie es punktuell in Ostbosnien tat. ${ }^{205}$ Doch ein solches Vorgehen war weder von den Diplomaten in Kroatien noch von der Staatsspitze in Berlin erwünscht und blieb daher aus. Aufgrund der Ustascha-freundlichen Politik sowie des Unterlassens jeglicher Hilfestellungen machten die Verfolgten die Wehrmacht für die Verbre-

202 Millo: L'Italia e la protezione degli Ebrei, S. 372.

203 Friedländer, Saul: The Extermination of the European Jews in Historiography. Fifty Years later, in: Bartov, Omer (Hg.): The Holocaust. Origins, Implementation, Aftermath, London/New York 2000, S. 79-89, hier S. 83 f.

204 BArch, RH 31/III/1, Nr. 11, Fernschreiben des Dt. Bev. Generals in Kroatien, 20.5.1941; Zur deutschen Divide-et-impera-Politik in Jugoslawien und der Sowjetunion siehe: Feferman, Kiril: Nazi „divide et impera“: Comparing Soviet and Yugoslavian Cases in 1941, in: Istorija 20. Veka (2016) 1, S. 97-108.

205 BArch, RH 31/III/1, Nr. 29, Fernschreiben des Dt. Bev. Generals in Kroatien, 10.7.1941; Korb: Im Schatten des Weltkriegs, S. 364. 
chen der Ustascha mitverantwortlich. Dies minderte deutlich ihre Bereitschaft, die Deutschen im Kampf gegen die Aufständischen zu unterstützen. ${ }^{206}$

Während sich die Deutschen also gegenüber den Kroaten, Serben und Muslimen desinteressiert zeigten, sich dann aber über die Verfolgung der Serben aus militärischen Gründen beschwerten, war die Situation der Juden freilich eine andere. Während sie auf allen anderen Gebieten versagte, erfüllte die Ustascha bei der Verfolgung der jüdischen Bevölkerung Kroatiens genau die in sie gesetzten Erwartungen. Das Reich gab die Richtung vor und alles andere erledigte zunächst die Ustascha. Erst als die kroatischen Methoden die deutsche Gründlichkeit vermissen ließen, griffen im Sommer 1942 das RSHA und der deutsche Polizeiattaché ein und organisierten gemeinsam mit der Ustascha die letzten Deportationen. Die Wehrmacht war im NDH - anders als in Serbien nur am Rande an der Verfolgung der Juden beteiligt. Diese Arbeitsteilung spiegelt sich letztlich auch in den Zahlen wieder: Die Ustascha ist für die Ermordung von 21.000 bis 23.000 bzw. ca. 74,6 Prozent der Juden Kroatiens und die Deutschen für 7.200-7.700 oder 25 Prozent verantwortlich. Die Italiener hingegen tragen die Verantwortung für ca. 130 oder 0,4 Prozent der jüdischen Opfer. ${ }^{207}$

Mit den Volksdeutschen hatte das Reich eine Art „fünfte Kolonne“ im NDH, die manches für den deutschen Besatzer erleichterte. Sie konnten bei der Durchsetzung der Interessen des Reichs und insbesondere bei der Bekämpfung des Aufstands als auch bei der Verfolgung der Juden auf die Volksdeutschen zählen. Darüber hinaus stellten sie eine Verbindung zwischen dem Reich und dem kroatischen Staat her, auf die der italienische Achsenpartner nur neidisch sein konnte. Die Italiener Dalmatiens konnten keine ähnliche Rolle übernehmen, da sie durch die Annexion aus dem kroatischen Staat herausgelöst und zu italienischen Staatsbürgern geworden waren.

206 BArch, RH 31/III/13, Bl. 6 f., Bericht von Arthur Häffner, 21.6.1941; BArch, RH 26/114/21, Propagandabericht, 24.6.1943.

207 Cvetković: Holocaust, S. 172. 